Federal Reserve Bank of Dallas

Globalization and Monetary Policy Institute

Working Paper No. 121

http://www.dallasfed.org/assets/documents/institute/wpapers/2012/0121.pdf

\title{
In the Shadow of the United States: The International Transmission Effect of Asset Returns*
}

\author{
Kuang-Liang Chang \\ National Chiayi University \\ Nan-Kuang Chen \\ National Taiwan University \\ Charles Ka Yui Leung \\ City University of Hong Kong
}

July 2012

\begin{abstract}
We examine how fluctuations in financial and housing markets in U.S. affect asset returns and GDP in Hong Kong. In contrast to the results from linear specifications, which concludes that the U.S. and Hong Kong are virtually delinked in terms of the asset markets, our regime-switching models indicate that the unexpected shock of US stock returns, followed by the TED spread, has the most significant effect on HK asset returns and GDP, typically in the regime with high return and low volatility. For the in-sample one-step-ahead forecasting, US Term spread stands out to be the best predictor.
\end{abstract}

JEL codes: E30, F40, G10

\footnotetext{
* Kuang-Liang Chang, Department of Applied Economics, National Chiayi University, 580 Sinmin Road, Chiayi City 60054, Taiwan. 866-5-2732852. klchang@mail.ncyu.edu.tw. Nan-Kuang Chen, Department of Economics, National Taiwan University, 21 Shuchow Road, Taipei 10021, Taiwan. 886-2-2351-9641 ext. 471. nankuang@ntu.edu.tw. Charles Ka Yui Leung, Department of Economics and Finance, City University of Hong Kong, Kowloon Tong, Hong Kong. 852-2788-9604. kycleung@cityu.edu.hk. Acknowledgement: We are grateful to (alphabetical order) Wing Hong Chan, Bob Edelstein, Andrew Filardo, Eric Hanushek, Dong He, Ivan Jaccard, Fred Kwan, Tommy Leung, Yue Ma, Miki Seko, Dragon Tang, Byron Tsang, Peng Wang, Isabel Yan, Frank Ying, Matthew Yiu, Jiro Yoshida, especially Thomas Lubik's careful reading of different drafts of this paper, and seminar participants at City Unviersity Workshop on macroeconomics and monetary policy, HKIMR Summer Workshop, NUS symposium on Asian real estate market, Taiwan Economic Association meeting for many useful comments and suggestions. Edward Tang provides excellent research assistance. The work described in this paper was partially supported by a grant from the Research Grants Council of the Hong Kong Special Administrative Region, China [Project No. CityU 144709]. Chen thanks the Public Economic Research Center (PERC), College of Social Science, National Taiwan University for financial support as well. The usual disclaimer applies. The views in this paper are those of the authors and do not necessarily reflect the views of the Federal Reserve Bank of Dallas or the Federal Reserve System.
} 
"Traditionally, Federal Reserve monetary policy has focused on the domestic economy. Although international factors have not been ignored, they have been subordinate to domestic concerns.... Recent trends and developments, however, suggest this domestic orientation may not be entirely satisfactory for U.S. monetary policy. There is a growing recognition of the fact that financial capital is increasingly mobile, and financial markets are evermore globally integrated. At the same time, varying degrees of dollarization have occurred in several emerging market economies and the dollar remains the world's principal international currency despite evolving developments in exchange rate arrangements. These considerations have a number of important implications for U.S. monetary policy. For example, they help to explain why changes in U.S. monetary policy can have increasingly potent effects on emerging market economies..."

U.S. Congress (Joint Economic Committee), 2000.

"Recent research suggests another possibility, which is that U.S. monetary policy actions may have significant effects on foreign yields and asset prices as well as on domestic financial prices. For example, changes in U.S. short-term interest rates seem to exert a substantial influence on euro area bond yields... and appear to have a strong effect on foreign equity indexes as well. In contrast, the effects of foreign short-term rates on U.S. asset prices appear to be relatively weaker."

Chairman Ben Bernanke, 2007.

\section{Introduction}

The potential significance of international transmission of fluctuations in economic activity and financial markets has gained increasing importance as interdependence across countries has rapidly risen during the last several decades. Increases in interdependence among economies may cause shocks or monetary policy in an economy spilling over to another via various transmission channels, such as close links in cross-border trades, foreign direct investment, global financial integration, and so on.

The transmission of shocks or monetary policy across economies has raised concerns 
because it might cause externalities on other economies' employment, output, asset returns, and financial stability. For example, the "contagion" of financial panic caused rapid outflow of capital and currency crisis in Latin America and East Asia in 1990s, and of liquidity crunch in money markets (especially commercial papers and repos) in 2007-08 subprime crisis (Brunnermeier and Pedersen, 2009; Corsetti et al., 1999; Demyanyk and Van Hemert, 2009; Gorton, 2007; Kaminsky and Reinhart, 2000; Peek and Rosengren, 2000; Radelet and Sachs, 1998; Taylor, 2009). Moreover, transmission in policy effect, leading to beggar-thy-neighbor, or even competitive devaluation, has stimulated a large literature on the potential gains from international monetary policy coordination (Corsetti and Pesenti, 2001, 2005; Obstfeld and Rogoff, 2002; Canzoneri et al., 2005; Benigno, 2002; and Benigno and Benigno, 2006; to name a few).

In particular, changes in both real and financial sectors in the United States (henceforth U.S. or $U S$ ) have long had an important influence on the rest of the world, primarily because of the size of U.S. economy and the role of U.S. dollar as a major reserve currency and medium of exchange for international trades and financial transactions. Our quotation from U.S. Congress (2000), Bernanke (2007), among others, have recognized such "asymmetry."

In this paper we focus on use Hong Kong as a case study on how the fluctuations in financial and housing markets in US would affect the asset returns and aggregate output of a small open economy. In particular, we would focus on the following questions. First, how do the U.S. financial markets affect the asset returns and aggregate output? Is it the expected component, the unexpected component, or the sum of the two? Second, which U.S. financial market variable tends to have the most significant impact on the asset returns and aggregate output? Third, do the U.S. financial market variables always have the same impact on the asset returns and aggregate output? Or, is it during the "crisis times" or "recessions" that the U.S. financial markets have more impact on Hong Kong (henceforth H.K. or $H K$ ) asset returns and aggregate output? Clearly, all these questions have important academic interest and policy implications. For instance, if we identify that it is the impact from U.S. to H.K. are different across regimes, the optimal policy for the local government could be regime-dependent. While it waits for more theoretical and structural modeling to provide a better answer, the current study may nevertheless 
be able shed light on the issue.

Hong Kong is selected for several reasons. First, Hong Kong is a small open economy and is too small to affect the United States. And when the authority in the United States make policy decisions, it is unlikely that the consequences on the Hong Kong economy will be taken into consideration. Hong Kong is also highly open to international financial markets and constantly subject to shocks from foreign countries. More importantly, Hong Kong has fixed her exchange rate between HK-US dollar to US $\$ 1$ for HK $\$ 7.8$ since October 1983 (so-called "LINK" exchange rate), by establishing a currency board through the Hong Kong Monetary Authority (HKMA). Hong Kong has essentially given up the independency of monetary policy and therefore will not have feedback effects in response to exogenous shocks originated from foreign countries. All these suggest that the relationship between the effects of foreign shocks and Hong Kong economy will be one-directional, which provides an unusual "natural experiment" to examine cross-country spillover effects. Thus, this paper naturally focuses on the period when Hong Kong has adopted the LINK exchange rate. Although the sampling period may be short relative to some earlier studies, it covers several important incidents, including the 1987 stock market crash in U.S., the Asian financial crisis, the current "global recession." It should be notice that during the whole sampling period, the same nominal exchange rate is maintained. And while many small open economies do not follow the same path, our results here may nevertheless serve as a benchmark for cross-country comparison.

We find that our two-step procedures yield dramatically different results from the ones delivered by linear VAR. First, the expected changes in U.S. financial and housing markets have almost no effect on the H.K. economy. Second, the unexpected shock of U.S. financial and housing markets are more likely to affect the asset markets than GDP in H.K., and the impact tends to occur in the state of high asset returns. Third, the unexpected shock of US stock returns has the most significant effect on H.K. asset returns and GDP, followed by the TED spread, and then the housing returns. ${ }^{1}$ Finally, for the in-sample one-step-ahead forecasting, US Term spread stands out to be the best predictor for the H.K. asset returns and GDP. The regime switching model with US Term spread (Model

\footnotetext{
${ }^{1}$ More discussion on the results will be presented in later sections.
} 
B) not only outperforms all other specifications of single regime and regime switching models, but also different specifications of 7-variate linear VAR models. Our result that the US term spread stands out to be the best predictor for the H.K. asset returns and GDP echoes the well-known finding following a large literature that the term structure contains information about future inflation, future real economic activities as well as asset returns. ${ }^{2}$ Clearly the term spread also wields a powerful spillover effect across countries. Overall, our results also suggest that regime-switching model may perform better the single-regime counterpart marginally.

The rest of the paper is organized as follows. Section 2 outlines the empirical models, where we consider five specifications of empirical models for the Hong Kong economy. Section 3 presents our baseline estimation results and conduct in-sample one-step-ahead forecasting. Section 4 concludes.

\section{The Empirical Models}

Our focus is to study how the U.S. economy may affect the H.K. GDP and asset prices. Since the macroeconomy and asset markets are closely related and may affect each other, a natural benchmark would be to use a linear VAR (vector auto-regressive) models with both the U.S. and H.K. variables. ${ }^{3}$ To our knowledge, this approach is not only used by some academics, but also some policy advice agencies. Formally, we have

$$
Y_{t}=C+A Y_{t-1}+U_{t}, U_{t}=\Sigma \times V_{t}, V_{t} \sim N(\mathbf{0}, R)
$$

\footnotetext{
${ }^{2}$ The robustness of forecasting power of the term spread has been confirmed by the data of the U.S. as well as other advanced countries. Among others, see Stock and Watson (1989), Plosser and Rouwenhorst (1994), Estrella and Mishkin (1997), Estrella and Hardouvelis (1991), Chang, Chen and Leung (2010), and the reference therein. For a review of the more recent literature, see Estrella (2005), among others.

${ }^{3}$ For instance, Chang et al (2010) also show that the inclusion of stock market return contributes to the prediction of the housing return, and vice versa. Econometrically speaking, Sims (1980), among others, discuss why the VAR approach may be superior than the single-equation approach in prediction and interpretation of the econometric results. See also Lubik and Schorfheide (2003, 2005).
} 
where $Y_{t}=[T E R M(U S), T E D(U S), S R E T(U S), H R E T(U S), S R E T(H K), H R E T(H K)$, $G D P(H K)]^{\prime}$, including term spread, TED spread, stock returns, and the housing returns of the U.S. ${ }^{4}$ and stock returns, housing returns and the GDP of H.K. ${ }^{5}$ The intercepts $C$ is a $7 \times 1$ vector, $\Sigma$ is a $7 \times 7$ diagonal matrix with diagonal elements $\sigma_{j}^{2}, j=1, . ., 7, V_{t}$ is a vector of standard normal distribution, $V_{t} \sim N(0, R)$, where the diagonal elements of the covariance matrix $R$ are unities and those of its off-diagonal elements are $\rho_{i j}^{\prime} s$, $i, j=1, . ., 7, i \neq j$, and $A$ is a $7 \times 7$ matrix. And to establish the robustness of the results, we consider three versions of linear VAR. The first two specifications, VAR(7)_1 and $\operatorname{VAR}(7) \_2$, do not impose any structural restrictions and they differ only the order of the last two variables. The third linear VAR model, VAR(7)_R, captures the earlier discussion that H.K. aggregate variables do not affect the U.S. economy. Thus, we restrict the model to be block-exogenous and several entries of the $A$ matrix to be zero to formalize the restriction that H.K. aggregate variables do not affect the U.S. counterpart,

$$
A=\left[\begin{array}{ccccccc}
a_{11} & a_{12} & a_{13} & a_{14} & 0 & 0 & 0 \\
a_{21} & a_{22} & a_{23} & a_{24} & 0 & 0 & 0 \\
a_{31} & a_{32} & a_{33} & a_{34} & 0 & 0 & 0 \\
a_{41} & a_{42} & a_{43} & a_{44} & 0 & 0 & 0 \\
a_{51} & a_{52} & a_{53} & a_{54} & a_{55} & a_{56} & a_{57} \\
a_{61} & a_{62} & a_{63} & a_{64} & a_{65} & a_{66} & a_{67} \\
a_{71} & a_{72} & a_{73} & a_{74} & a_{75} & a_{76} & a_{77}
\end{array}\right] .
$$

An alternative approach we propose here emphasizes on the non-linearity of the time series of both the U.S. and H.K. asset markets, as well as the asymmetry between H.K. and

\footnotetext{
${ }^{4}$ Following the literature, we use the difference between 10-year and 3-month US treasury securities as a measure of the term spread, and the difference between 3-month LIBOR and 3-month treasury bill as a measure of the US TED spread. The former attempts to capture the difference between long-term and short-term interest rates, and the latter attempts to capture the "tightness" of the interbank market.

${ }^{5}$ Implicitly, this formulation assumes that there are potentially important interactions among the stock market, the housing market and the aggregate economy. For theoretical justifications, see Cheng, Lin and Zeng (2010), Leung (2003, 2007), Leung and Teo (2009), among others.
} 
U.S. Formally, it proceeds with two steps. The first step extracts the unexpected shocks from the changes in the financial and housing markets of the U.S. economy. Unlike the case of linear VAR, however, expectation may change over time in the asset markets. For instance, it may depend on whether it is a "bull" or a "bear" market (among others, see Maheu and McCurdy, 2000), which suggests that a regime-switching model may be more appropriate. In addition, Chen and Leung (2008) show that in the context of a multi-period general equilibrium model that when there are heterogeneous financially constrained agents, the equilibrium relationship between the output (or, "fundamental") and the property price may be non-linear. Third, a regime-switching model is consistent with the observations of short-run predictability of the property price and the long-run non-profitability (due to stochastic regime switch) of property market investment. ${ }^{6}$ Moreover, in case the true model is indeed a single-regime one, the estimated parameters across regimes would be found to be very similar. Thus, the regime-switching model does allow for a more flexible structure. ${ }^{7}$ In this paper, we estimate a four-variable regime-switching VAR $(R S-V A R)$ model for the US economy:

$$
Z_{t}=C^{U S}\left(s_{t}\right)+A^{U S}\left(s_{t}\right) Z_{t-1}+U_{t}^{U S}
$$

where $s_{t}$ is the unobserved state variable, $s_{t} \in S=\{1,2\}, Z_{t}=[T E R M, T E D, S R E T, H R E T]^{\prime}$ includes term spread, TED spread, stock returns, and the housing returns. The vector of intercepts is $C^{U S}\left(s_{t}\right)=\left[C_{1}^{U S}\left(s_{t}\right), C_{2}^{U S}\left(s_{t}\right), C_{3}^{U S}\left(s_{t}\right), C_{4}^{U S}\left(s_{t}\right)\right]^{\prime}$. In this model, the "shocks" are captured by the residual term, which is defined to be

$$
U_{t}^{U S}=\Lambda^{U S}\left(s_{t}\right)\left(\Sigma^{U S}\right)^{1 / 2} V_{t}^{U S}\left(s_{t}\right),
$$

\footnotetext{
${ }^{6}$ The intuition is simple. If the regimes are persistent, then in the short run, the regime-switching model stays on a particular regime and hence behaves as if it is a simple linear model. Hence, we have the short-run predictability. On the longer run, however, stochastic regime switch will occur and since housing is relatively illiquid, investment strategies which based on the (single-regime) linear model would likely incur loss, and hence the long-run non-profitability.

${ }^{7}$ As the referee points out, regime-switching models may over-identify. This issue may be more serious in small sample. In the current context, we are unable to test whether the model over-identify. On the other hand, Leung, Cheung and Tang (2011) present evidence from transaction level data that there is a structural change in the house price and trading volume process. Thus, we consider it a worthwhile exercise to employ a regime-switching model on the Hong Kong data.
} 
where $\Sigma^{U S}$ is a $4 \times 4$ diagonal matrix with diagonal elements $\sigma_{j, U S}^{2}, j=1, \ldots 4$,

$$
\Sigma^{U S}=\left[\begin{array}{cccc}
\sigma_{1, U S}^{2} & 0 & 0 & 0 \\
0 & \sigma_{2, U S}^{2} & 0 & 0 \\
0 & 0 & \sigma_{3, U S}^{2} & 0 \\
0 & 0 & 0 & \sigma_{4, U S}^{2}
\end{array}\right]
$$

$\Lambda^{U S}\left(s_{t}\right)$ is a $4 \times 4$ diagonal matrix with diagonal elements $\lambda_{j, U S}\left(s_{t}\right), j=1, . ., 4$,

$$
\Lambda^{U S}\left(s_{t}\right)=\left[\begin{array}{cccc}
\lambda_{1, U S}\left(s_{t}\right) & 0 & 0 & 0 \\
0 & \lambda_{2, U S}\left(s_{t}\right) & 0 & 0 \\
0 & 0 & \lambda_{3, U S}\left(s_{t}\right) & 0 \\
0 & 0 & 0 & \lambda_{4, U S}\left(s_{t}\right)
\end{array}\right]
$$

which captures the difference in the intensity of volatility, and $V_{t}^{U S}\left(s_{t}\right)$ is a vector of standard normal distribution, $V_{t}^{U S}\left(s_{t}\right) \sim N\left(0, R^{U S}\left(s_{t}\right)\right)$, where the covariance matrix is given by

$$
R^{U S}\left(s_{t}\right)=\left[\begin{array}{cccc}
1 & \rho_{12}^{U S}\left(s_{t}\right) & \rho_{13}^{U S}\left(s_{t}\right) & \rho_{14}^{U S}\left(s_{t}\right) \\
\rho_{12}^{U S}\left(s_{t}\right) & 1 & \rho_{23}^{U S}\left(s_{t}\right) & \rho_{24}^{U S}\left(s_{t}\right) \\
\rho_{13}^{U S}\left(s_{t}\right) & \rho_{23}^{U S}\left(s_{t}\right) & 1 & \rho_{34}^{U S}\left(s_{t}\right) \\
\rho_{14}^{U S}\left(s_{t}\right) & \rho_{24}^{U S}\left(s_{t}\right) & \rho_{34}^{U S}\left(s_{t}\right) & 1
\end{array}\right]
$$

Now we describe how the state of nature, $s_{t}$, evolves over time. The Markov switching process relates the probability that regime $j$ prevails in $t$ to the prevailing regime $i$ in $t-1, \operatorname{Pr}\left(s_{t}=j \mid s_{t-1}=i\right)=P_{i j}^{U S}$. The transition probabilities are assumed to be fixed and the transition matrix of the US economy is given by:

$$
P^{U S}=\left(\begin{array}{cc}
P_{11}^{U S} & 1-P_{22}^{U S} \\
1-P_{11}^{U S} & P_{22}^{U S}
\end{array}\right) .
$$

Despite its simplicity, previous work (such as Chang et al, 2010, 2011a, b) find that this simple structure is capable to capture the interactive dynamics of the U.S. housing and stock markets reasonably well. Since the state of the economy is unobservable, we identify the regime for given a time period by Hamilton (1994) smoothed probability approach, 
in which the probability of being state $s_{t}$ at time $t$ is given by $\pi\left(s_{t} \mid \Omega_{T}\right){ }^{8}$ Given that we assume the state of nature shifts between two regimes in both economies, i.e., $s_{t} \in$ $S=\{1,2\}$, we identify the economy most likely to be in state $j$ if $\pi\left(s_{t}=j \mid \Omega_{T}\right)>0.5$, $j=1,2$.

Given estimated residuals of the U.S. economy from (2), the second step is to estimate the following $R S$-VAR model for Hong Kong:

$$
X_{t}=C^{H K}\left(\omega_{t}\right)+A^{H K}\left(\omega_{t}\right) X_{t-1}+\gamma_{z}\left(\omega_{t}\right) z_{t-1}^{i}+\gamma_{u}\left(\omega_{t}\right) \widehat{u}_{t}^{i, U S}+U_{t}^{H K},
$$

where $\omega_{t}$ is the state variable of the H.K. economy, $\omega_{t} \in W=\{1,2\}, X_{t}=[S R E T, H R E T, G D P]^{\prime}$ includes stock returns, housing returns, and real GDP growth of the Hong Kong economy. Clearly, this RS-VAR is constructed to be similar but not identical to the one for the U.S. economy. The difference is reflected in the two terms representing the effect from the U.S.: $(i) z_{t-1}^{i} \in Z_{t-1}$ is an element of the vector of lagged aggregate variables of US from, $i=T E R M, T E D, S R E T, H R E T$, and hence should be expected with quarterly frequency data, and $(i i) \widehat{u}_{t}^{i, U S}$ is its corresponding residual term from (2), i.e. the unexpected effect obtained from the RS-VAR model of the US economy. ${ }^{9}$ Notice that in the linear case, $Z_{t-1}$ and $\widehat{U}_{t}^{U S}$ would be orthogonal to each other. The coefficient vectors of these two terms are respectively $\gamma_{z}\left(\omega_{t}\right)=\left[\gamma_{z 1}\left(\omega_{t}\right), \gamma_{z 2}\left(\omega_{t}\right), \gamma_{z 3}\left(\omega_{t}\right)\right]$ and $\gamma_{u}\left(\omega_{t}\right)=\left[\gamma_{u 1}\left(\omega_{t}\right), \gamma_{u 2}\left(\omega_{t}\right), \gamma_{u 3}\left(\omega_{t}\right)\right] .^{10}$

\footnotetext{
${ }^{8}$ The idea is that we identify the state of the economy from an ex post point of view, and thus, not only the set of information up to period $t$, but also the full set of information is employed.

${ }^{9}$ Formally, it means that $U_{t}^{U S}=Z_{t}-\left[\widehat{C}^{U S}\left(s_{t}\right)+\widehat{A}^{U S}\left(s_{t}\right) Z_{t-1}\right]$, where $\widehat{C}^{U S}\left(s_{t}\right), \widehat{A}^{U S}\left(s_{t}\right)$ are the matrices of coefficients estimated from (2). Clearly, in the context of regime-switching models,$U_{t}^{U S}$ may compose of forecasting error conditioning on the regime persists between time $t$ and $(t+1)$, or forecasting error due to a regime change, among other errors. Measurement in one regime can also spill-over to other regime. Given the data constraint, we cannot propose any feasible alternative, but only acknowledge the limitations. For related discussion, see Cosslett and Lee (1985), among others.

${ }^{10}$ An alternative formulation would be to include the whole vector of US variables. Thus, (4) will be replaced by $X_{t}=C^{H K}\left(w_{t}\right)+A^{H K}\left(w_{t}\right) X_{t-1}+\gamma_{z}\left(w_{t}\right) Z_{t-1}+\gamma_{u}\left(w_{t}\right) \widehat{U}_{t}^{U S}+U_{t}^{H K}$, where $\gamma_{z}\left(w_{t}\right)$ and $\gamma_{u}\left(w_{t}\right)$ are $3 \times 3$ matrices. However, this alternative formulation demands many more coefficients to be estimated at the same time. Given very limited time periods in our sample, this will lead to very imprecise estimates, if it converges at all. We therefore employ (4) to capture the dynamics for Hong Kong.
} 
Again, the residual term is similarly defined,

$$
U_{t}^{H K}=\Lambda^{H K}\left(\omega_{t}\right)\left(\Sigma^{H K}\right)^{1 / 2} V_{t}^{H K}\left(\omega_{t}\right),
$$

where where $\Sigma^{H K}$ is a $3 \times 3$ diagonal matrix with diagonal elements $\sigma_{j, H K}^{2}, j=1, . ., 3$, $\Lambda^{H K}\left(\omega_{t}\right)$ is a $3 \times 3$ diagonal matrix with diagonal elements $\lambda_{j, H K}\left(\omega_{t}\right), j=1, . ., 3$, and $V_{t}^{H K}\left(\omega_{t}\right)$ is a vector of standard normal distribution, $V_{t}^{H K}\left(\omega_{t}\right) \sim N\left(0, R^{H K}\left(\omega_{t}\right)\right)$. Finally, the transition matrix of the Hong Kong economy is given by:

$$
P^{H K}=\left(\begin{array}{cc}
P_{11}^{H K} & 1-P_{22}^{H K} \\
1-P_{11}^{H K} & P_{22}^{H K}
\end{array}\right) .
$$

Again, given that we assume the state of nature shifts between two regimes in both economies, i.e., $\omega_{t} \in W=\{1,2\}$, we identify the economy most likely to be in state $j$ if $\pi\left(\omega_{t}=j \mid \Omega_{T}\right)>0.5, j=1,2$. Obviously, relative to the linear VAR approach (such as (1)), our two-step approach enables to (a) distinguish the impact of the expected U.S. variables versus the unexpected component on the H.K. variables, and (b) estimate the potentially regime-dependent responses of the H.K. economy to the U.S. variables. Since we do not know which model is a better description of the reality, we consider five specifications of empirical models for the Hong Kong economy, as outlined in Table 1. As a benchmark, Model A does not include any effect from the US, and Model B-E each includes a pair of variables representing the expected and unexpected effect of the US financial or housing market.

[Table 1 about here]

\subsection{Data Sources}

Our objective to understand the interactive dynamics between the housing market return and the stock market, among other variables have implications to our estimation strategy. Since the house price indices in both US and Hong Kong are available only in quarterly data, other variables originally available in monthly are transformed into quarterly, covering the period of $1984 Q 1-2009 Q 4$. This period gives us the longest time series accessible to the authors with the same and fixed nominal exchange rate between the currencies of US and Hong Kong. 
All of our data are obtained from public sources. We begin our description from the four variables employed by the US model economy, (2). We compute the real house returns $\left(H R E T_{t}\right)$ from the OFHEO housing price index, deflated by the GDP deflator. The OFHEO house price index is taken from the Office of Federal Housing Enterprise Oversight. Since housing price index is available only in quarterly data, the interest rates originally available in monthly are transformed into quarterly. For the term spread TERM, we follow Estrella and Trubin (2006) by choosing the spread between ten-year Treasury bond yield and three-month Treasury bill rate, and both are released by the Federal Reserve Board of Governors. As for the 3-month Treasury bill rate, we use the secondary market three-month rate expressed on a bond-equivalent basis. ${ }^{11}$ Estrella and Trubin (2006) argue that this spread provides an accurate and robust measure in predicting U.S. real activity over long periods of time. Finally, the TED spread (TED) is the difference between the 3-month Eurodollar deposit rate and the 3-month T-bill rate.

Hong Kong data are available from the Hong Kong government website. ${ }^{12}$ All asset returns are taken to be the percentage of annualized return, defined as $100 \times\left(R E T_{t}-R E T_{t-4}\right)$. We then deflate these returns by CPI to obtain their real returns.

\subsection{Summary Statistics}

Before a formal statistical analysis, it may be instructive to have an overview of the data series to be used. Details are provided in the appendix, and we only highlight a few regularities here. ${ }^{13}$ First, the average stock returns in U.S. and H.K. are higher than the average housing returns. Predictably, they are accompanied by larger risk: the standard deviations of stock returns in both countries are also larger than those of housing

\footnotetext{
${ }^{11}$ The 3-month secondary market T-bill rate provided by the Federal Reserve System is on a discount basis. We follow Estrella and Trubin (2006) by converting the three-month discount rate $\left(r^{d}\right)$ to a bond-equivalent rate $(r): r=\frac{365 \times r^{d} / 100}{360-91 \times r^{d} / 100} \times 100$.

12 http://www.gov.hk/en/residents/.

${ }^{13}$ The full version (with appendix) is available at http://mpra.ub.uni-muenchen.de/32776/1/MPRA_paper_32776.pdf
} 
returns. Second, the volatilities of stock and housing returns in H.K. are very different from those in U.S.. For example, the standard deviations of stock and housing returns in U.S. are 17.519 and 3.373, respectively, while those in H.K. are 28.126 and 16.471, respectively. The standard scores (i.e. standard deviation relative to the means) of stock and housing returns in U.S. are 4.507 1 and 2.4442, respectively, while those in H.K. are 3. 5567 and 4.5715, respectively. Thus, in U.S., the stock return is more volatile than the housing return, while it is the other way in Hong Kong. Third, the U.S. term spread and TED spread show only negligible correlation, suggesting that these two spreads measure different types of risk. Finally, the correlation between stock and housing returns in H.K. (0.395) is slightly larger than that in U.S. during the same period (0.228). ${ }^{14}$

[Table 2 about here]

\section{Baseline Results}

While the detailed results of the linear VAR models are presented in the appendix, we summarize them here. (1) Both the point estimates of the coefficients and the overall performance (measured by $\ln L$ and AIC) are very similar across models. (2) In general, $\left\{a_{i j}\right\}$ (i.e. elements of $A$ in (1)) tend to be statistically insignificant for $i \neq j$. Also, most of the $\left\{\rho_{i j}\right\}$ (i.e. off-diagonal elements of $R$ in (1)) are also statistically insignificant. Thus, if we believe the linear VAR models to be a good approximation of the "true model", we may be tempted to conclude that there are limited interactions between the U.S. economy and the Hong Kong asset returns and aggregate output. Clearly, this view may have very different policy implications than those commonly believed.

We now turn to the "hierarchical Markov regime-switching framework" proposed in this paper, represented by (2) and (4). We first estimate the Markov switching version of

\footnotetext{
${ }^{14}$ For more discussion on the Hong Kong housing market, see Leung, Cheung and Tang (2011), Leung and Tang (2011), among others.
} 
equation (2) for the U.S. economy. The estimated regime 1 turns out to have significantly lower mean return and at the same time high volatility on asset. In other words, regime 1 is the "high risk and low return" regime. The transition probability matrix is estimated to be

$$
P^{U S}=\left(\begin{array}{cc}
P_{11}^{U S} & 1-P_{22}^{U S} \\
1-P_{11}^{U S} & P_{22}^{U S}
\end{array}\right)=\left(\begin{array}{cc}
0.747 & 0.075 \\
0.253 & 0.925
\end{array}\right)
$$

Note that the transition probability of regime US1 (0.747) is much smaller than that of regime US2 (0.925). Thus, regime US1 ("bear market") is less persistence than regime US2 ("bull market"). By Figure 1, we can see that the estimated smoothed probabilities for regime 1 (indicated by shaded areas, accounting for $24 \%$ of total sample periods) are closely associated with low returns in stock and housing returns. (See the appendix for more details).

[Figure 1 about here]

Given the estimates of the U.S. economy, we proceed to study how the U.S. financial and housing markets affects the housing and stock returns in Hong Kong. To save space, we provide only the summary of the results here. The details of the estimation results are reported in the appendix.

Table 3 reports the identified regime 1 (HK1) for H.K. under those five models. The time periods identified to be regime HK1 for these models are very similar. The are mainly two periods of time: 1984Q2-1987Q3, and 1998Q1-1998Q3. The former is associated with the U.S. S\&L crisis and 1987 stock market crash, and the latter is closely related to the Asian financial crisis. The estimated regime-switching models seem to be able to capture major turbulences in Hong Kong. ${ }^{15}$

Table 4 summarizes the AICs under different model specifications. In particular, we consider the cases when (2) is a linear VAR and compare the cases when (2) is allowed to

\footnotetext{
${ }^{15}$ Notice that the Post Global Financial Crisis period (PGFC, i.e. the period after the bankruptcy of the Lehman Brothers) is not identified as regime 1. A possible reason is that while the stock market and the GDP drops significantly during the period, the housing market rebounds quickly and significantly. Since the computer program identify a regime change for the whole system, the PGFC is not identified as a scenario of regime 1. For more discussion, see Leung and Tang (2011).
} 
be a regime-switching model. It is clear that for all models allowing for regime switching performs better than linear specification in terms of AIC.

[Table 3, 4 about here]

Table 5 summarizes the impacts of expected and unexpected U.S. financial and housing markets on H.K. asset returns and GDP growth. Overall, our "two step estimation procedure" suggests a tight connection between the U.S. financial market variables and the Hong Kong asset returns and macro-economy. First, the expected changes in U.S. financial and housing markets have almost no effect on the H.K. economy. This result is consistent to the rational expectation hypothesis that agents (and hence the market) will "factorin" all expected changes. Second, the unexpected shocks of U.S. financial and housing markets are more likely to affect the asset markets than GDP in H.K.. Notice that even when the equation (4) is estimated as a single-regime regression model, the coefficients of several un-expected components of U.S. are still statistically significant. ${ }^{16}$ This is in sharp contrast to the linear VAR models when the "expected" and "unexpected" components are combined together and they were found to have insignificant impact to the H.K. asset returns and GDP. Moreover, if we estimate (4) as a regime-switching model, we find that the impact of unexpected shocks from U.S. tends to occur in regime HK2 (the "normal times", with relative higher asset returns and lower volatility). ${ }^{17}$

[Table 5 about here]

\footnotetext{
${ }^{16}$ As it is shown in Chong, Lam and Yan (2011), Chong and Yan (2011), among others, the standard errors under a two-step procedure tend to be larger than the OLS counterparts. Thus, while our model yields unbiased estimates of the coefficients, we tend to under-evaluate the statistical significance of those coefficients in the regime-switching models. Since correcting for the standard error estimation is very difficult in a hierarchical regime-switching VAR context, and the coefficients that we identify as statistically significant would only improve should the correction is made, we only acknowledge this issue and proceed.

${ }^{17}$ A possible reason why the parameters in regime HK1 are mostly insignificant is that we only have 16 observations in regime HK1 (taking model A as an example), but we have at least 16 parameters to be estimated. The insufficient observations may cause the large standard errors, as we can observe that the standard errors of estimated parameter are larger in regime HK1 than in regime HK2 in these models.
} 
Third, the U.S. Term spread, either expected or unexpected, shows no effect on the asset returns or GDP in H.K.. Finally, the unexpected shock of stock returns (Model D) in U.S. appears to have the most significant impact on H.K. asset returns and GDP, followed by the TED spread (Model C), and then the housing returns (Model E). An usual explanation of cross-country stock return co-movements is the re-balancing of portfolio of international investors, which can be "large" and their actions can influence the market prices. On the other hand, this paper employs quarterly data and hence the "re-balancing portfolio" may be less important. Rather, it may be that the stock return does contain some information about future economic growth of the United States. Similarly, an unexpected change in the TED spread may signal a change in the credit market condition. Since "money" can move across borders, a contraction in the U.S. credit market is soon translated into a contraction in the H.K. credit market, which will affect both the asset prices and the aggregate output. It can also affect the subsequent economic growth of the United States. Since U.S. is an important international trade partner of Hong Kong, an alternation of the U.S. economic growth would be translated into a change in future export growth in Hong Kong, and hence affect the asset prices. This explanation is also consistent with some earlier research that international trade plays an important role in the economic growth of Hong Kong, and hence the asset prices. ${ }^{18}$

In addition, Table 5 also suggests that in general, it is during the regime 2 , i.e. the "normal time" that the U.S. financial market variables have a larger impact on the H.K. asset returns and aggregate output (in terms of recording statistical significance of the U.S. variables). Now recall that when linear VAR models are regressed, most of the off-diagonal elements of $A$ and $R$ in (1) are statistically insignificant, and one may be tempted to conclude that the U.S. financial variables do not have that much influence on the H.K. counterpart based on those VAR. Now when we compare that with our "hierarchical regime-switching model," we find that it is the unexpected component of the U.S. variables which have impact on the H.K. variables. Furthermore, most of the

\footnotetext{
${ }^{18}$ For more on the interbank market channel to the real economy, see Davis (2010), Gertler and Kiyotaki (2010), among others. For the trade-growth channel in Hong Kong, see Chou and Wong (2001), Ho and Wong (2008), among others.
} 
impacts seem to concentrate in regime 2 (the "normal times"). Thus, when we regress the linear VAR models, we effectively pool the expected and unexpected parts, as well as the "normal times" and "crisis times" together. Since the unexpected part is random, and the switching across regimes is also random, it might result in "insignificant statistical relations" between the U.S. financial variables and H.K. counterparts. Needless to say, this is only a hypothetical explanation and due to the data limitation, we can only leave the issue to the future research.

\section{$3.1 \quad$ In-Sample Forecasting}

The previous section shows that the linear VAR models and our "hierarchical" regimeswitching models tend to suggest very different relationships between the U.S. financial market and the Hong Kong counterparts. It is natural to ask which type of models is more reliable. In the econometrics literature, many measures have been suggested. Given the limitations of our dataset and the journal space, we focus on the comparison of insample forecasting. In particular, we examine the in-sample one-step-ahead forecasting of $X_{t}=[S R E T, H R E T, G D P]^{\prime}$, which includes stock returns, housing returns, and real GDP growth of the Hong Kong economy. Given the specification of H.K. in (4), the one-step-ahead forecast for $x_{t} \in X_{t}$ is given by

$\widehat{x}_{t+1 \mid t}=\sum_{\omega_{t+1}=1}^{2} P\left(\omega_{t+1} \mid I_{t}\right)\left[C^{H K}\left(\omega_{t+1}\right)+A^{H K}\left(\omega_{t+1}\right) X_{t}+\gamma_{z}\left(\omega_{t+1}\right) z_{t}^{i}+\gamma_{u}\left(\omega_{t+1}\right) \widehat{u}_{t+1}^{i, U S}\right]$,

where $\widehat{u}_{t+1}^{i, U S}$ is $i$-th element of the residual term at $t+1$ obtained from U.S. model (2), and $i=T E R M, T E D, S R E T, H R E T$.

To evaluate the performances of in-sample forecasts of these models and different specifications, we compute two widely-used measures, Root Mean Square Errors ( $R M S E)$ 
and Mean Absolute Errors $(M A E)$, which are defined respectively as

$$
\begin{aligned}
R M S E(1) & =\left[\frac{1}{T-1} \sum_{t=1}^{T-1}\left(x_{t+1}-\widehat{x}_{t+1 \mid t}\right)^{2}\right]^{1 / 2} \\
M A E(1) & =\frac{1}{T-1} \sum_{t=1}^{T-1}\left|x_{t+1}-\widehat{x}_{t+1 \mid t}\right|
\end{aligned}
$$

where $\widehat{x}_{t+1 \mid t} \in \widehat{X}_{t+1 \mid t}$. Clearly, the RMSE tends to penalize "big mistakes" more than the MAE. Due to the data limitation, we restrict our attention to one-step in-sample forecast. The results are reported in Table $6 \mathrm{a}-6 \mathrm{c}$, corresponding to the forecasts of stock returns, housing returns, and real GDP growth, respectively, of Hong Kong. Several interesting observations are in order.

[Table 6a-6c, Figure 2 about here]

First, except the RMSE comparison for model A, for all models A-E the specification of regime-switching performs better than that of single-regime does in in-sample forecasting. Now, recall the result in Table 5 that U.S. stock returns (Model D) and TED spread (Model C) are the two most significant factors affecting the H.K. asset returns and GDP. However, these two variables do not perform well in forecasting. Among these five models, Model B with regime switching has the lowest MAE and RMSE (except for the GDP forecasting) all around, which means that U.S. Term spread stands out to be the best predictor for the H.K. asset returns and GDP. ${ }^{19}$

\footnotetext{
${ }^{19}$ It should be noticed that while un-expected stock return has the best explanatory power individually, model D (which contains the stock return of U.S.) needs not provide the best forecasting. Notice that our measures of forecasting performance is MAE and RMSE, which is in a sense a weighted average of the forecast errors in different periods. Thus, it is possible that model D may have some predicted some periods really badly that will bring down its "average performance." In addition, when we compare the forecasting performance across models, we include both the expected and un-expected part of the financial asset return or housing return, and hence may give a different result than the previous section which focuses on the explanatory of the explanatory power of individual variable.
} 
We also report the forecasting performance of the 7-variate linear VAR models in the last three row of Table 6a-6c to facilitate the comparison. The predictive performance of the "naive" VAR models and the restricted VAR model are as least comparable to quite a few regime switching models in terms of either MAE or RMSE. For example, in forecasting H.K. stock returns (Table 7a), the restricted VAR model, VAR(7)_R, performs better than all single regime models $\mathrm{A}-\mathrm{E}$ and regime switching model $\mathrm{C}$ in terms of MAE. Moreover, the "naive" VAR models, $\operatorname{VAR}(7) \_1$ and $\operatorname{VAR}(7) \_2$, performs better than all single regime models A-E and regime switching models A, C and D, when evaluated in terms of RMSE. Nevertheless, Model B (with U.S. Term spread) with regime switching still outperforms all 7-variate linear VAR models in forecasting H.K. stock returns, housing returns, and GDP growth, except for the forecasting of GDP growth when evaluated in terms of RMSE. To provide a visualization, Figure 2 shows the estimated smoothed probabilities for regime 1 (indicated by shaded areas, accounting for $14.6 \%$ of total sample periods) of Model B. The matrix of the transition probability is

$$
P=\left[\begin{array}{ll}
0.9166 & 0.0207 \\
0.0834 & 0.9793
\end{array}\right]
$$

Notice that both regimes are very persistent, which will exhibit "short run predictability", as in the case of the U.S. (see Chang et al., 2011). ${ }^{20}$

\subsection{Impulse Responses}

To gain more intuitions of the predictions of alternative models, this subsection presents the impulse response analysis of the unexpected changes in term spread, TED spread, stock return returns, and housing returns of the U.S. respectively on the H.K. variables (stock returns, housing returns, and the GDP). Given the discussion above, we will focus on the regime-switching Model B and the linear restricted model VAR(7)_R. To implement the impulse response function in our two-step estimation approach, we follow the approach of Garcia and Schaller (2002). ${ }^{21}$ The results are plotted in Figure 3-6. The first column

\footnotetext{
${ }^{20}$ The plots of other models are available upon request.

${ }^{21}$ Recall that for $\operatorname{VAR}(7)$ R, only the U.S. variables would affect the HK variables but not vice versa. Similarly, in the regime-switching model B, the influence of US variables to HK varibles is uni-directional.
} 
is the impulse response for the restricted linear model VAR(7)_R, while the remaining columns are the single-regime, regime 1 , and regime 2 respectively for Model $\mathrm{B}^{22}$

Some interesting observations are as follows. First, Figure 3-6 show that an unexpected rise in term spread, a decline in TED spread, or a rise in stock returns in U.S. signals a booming economy, which spills over to Hong Kong, resulting a rise in stock returns, housing returns, and GDP. However, an unexpected rise in U.S. housing returns does not clearly generate a positive spillover effect on Hong Kong economy.

Second, the impulse responses of Model B, either single-regime or regime-switching, are less persistent than those of the restricted linear model VAR(7)_R, except that the impulse responses of regime 1 (bust regime) in Model B appear to be divergent given any unexpected shock. This may be due to estimation imprecision, as there may not be enough data points to be identified as "regime 1."

Third, among these shocks from the U.S., it seems that a stock return shock exerts the largest spillover effect on the Hong Kong economy. Moreover, Hong Kong's stock return appear to be most sensitive to the spillover effect, followed by housing returns and then GDP.

[Figure 3-6 about here]

\subsection{Robustness Check}

On top of the MAE and RMSE statistics we have just calculated, we also adopt the Diebold-Mariano (1995) test to assess the "relative performance" of different models. The test aims to test the null hypothesis of equality of expected forecast accuracy, in terms of a loss function, against the alternative of different forecasting ability across models.

Let $\left\{x_{t}\right\}$ denote the series to be forecast and let $x_{t+h \mid t}^{i}$ be the model $i^{\prime}$ s $h$-step forecast of $x_{t+h}$ based on the information at time $t, h>0$. Let $e_{t+h \mid t}^{i}$ be the forecasting error of model $i, e_{t+h \mid t}^{i} \equiv x_{t+h}-x_{t+h \mid t}^{i}$. The Diebold-Mariano (henceforth $D M$ ) test is based on

\footnotetext{
${ }^{22}$ We also conduct impulse responses of expected changes in US aggregate variables on stock returns, housing returns, and the GDP of HK for Model B and the linear restricted model VAR(7)_R. They are available upon request.
} 
the loss differential,

$$
d_{t}=L\left(e_{t+h \mid t}^{i}\right)-L\left(e_{t+h \mid t}^{j}\right)
$$

where $L(\cdot)$ is some loss function. Clearly, if the two models have roughly the same predictive power, the expectation of the loss differential will be zero, $E\left[d_{t}\right]=0$. If, instead, model $i$ predicts better (worse) than model $j$, the expected value of the loss differential will be significantly negative (positive). ${ }^{23}$ Limited by data availability, we here focus on the case when $h=1$.

The results are reported in Table 7a-7c. Since DM test is conducted pairwise, we use Model B (with U.S. Term spread) as the benchmark to be compared with, i.e., the model $i$ in the statistic (6). Therefore, if Model B performs better, the value of D-M statistic in the tables will be significantly negative.

In the previous sub-section, Model B is found to have the best forecasting performance in terms of MAE and RMSE. However, under D-M statistics Model B performs significantly better in prediction than only Model D in stock returns and (partly) GDP growth. Even though almost all of the statistics are negative in these three tables, they are mostly insignificant. Therefore, the significance in the forecasting performance of Model B over other models is not evident in terms of the DM statistics.

The inability for the Model B to provide superior prediction than other models may simply reflect a typical dilemma of empirical research in Asian countries. Typically, Asian countries have much shorter time series data than the U.S. and European countries. If large number of variables is chosen in the econometric model, the model would need to compromise in the functional form, and hence may mask the potential non-linear relationship among different variables. If instead a flexible functional form is selected, the number of parameters typically increase exponentially with the number of variables. As a result, the number of variables that can be included in the econometric model would be limited.

\footnotetext{
${ }^{23}$ The DM statistics will depend $\bar{d}$, which is an average value of $d_{t}$, for different period $t$, and the co-variance of $d_{t}$ and $d_{t-k}, k=1,2,3, \ldots$ As shown by Zivot (2004), other things being equal, if model $i$ which consistently over-predict in some sub-period and then consistently under-predict in other subperiod, it is more likely to get not only a lower value of $d_{t}$ in different period $\mathrm{t}$, but also a higher value of co-variance $d_{t}$ and $d_{t-k}, k=1,2,3, \ldots$ As a result, model $i$ is would be classified as under-perform the alternative model. See Zivot (2004) for more details.
} 
As a matter of fact, this is why we have Model $\mathrm{B}^{\sim} \mathrm{E}$, instead of putting all U.S. variables into the same model. The fact that no "clear winner" is identified among different models may suggest that different variable may indeed carry some independent and comparable important information and hence our approach of taking each variable in one model may not be able to generate the ideal result. Unfortunately, other than waiting for more data to come in the future years, it seems that this dilemma cannot be easily solved with the traditional approach. Future research may explore alternative methodology, such as the Bayesian approach. Another possibility is to follow the unobservable factor approach (e.g. Stock and Watson, 2002). Better prediction may be obtained at the price of an increased difficulty of getting straightforward interpretation for the econometric results. Therefore, future research may want to compare the "gains" versus "losses" over different approaches as well.

[Table 7 about here]

\section{Concluding Remarks}

Due to the increasing importance of interdependence across economies during the last several decades, via the linkage in trade and financial integration, the potential significance of international transmission of fluctuations in economic activity and financial markets has gained more and more attention. If a shock originated from one economy transmitting to another, the latter may try to counteract the potential impact of the foreign shock using its monetary policy. However, the reaction in monetary policy will tend to mitigate or even neutralize the effect of international transmission of an exogenous shock.

In order to precisely measure the effect of international transmission of an exogenous shock, we take the U.S.-Hong Kong relationship as a case study. The reasons are two-fold. First, due to the dominant role of the U.S. economy in international trade and international financial transactions, changes in both real and financial sectors in the U.S. have an important influence on the rest of the world. Second, by design, the currency board of Hong Kong is refrained from conducting monetary policy, and thus there will be no 
feedback effects in response to exogenous shocks originated from foreign countries. Therefore, the case of Hong Kong provides a "natural experiment" to study the international transmission of changes in both real and financial sectors in the U.S.

Our linear specifications suggest that the U.S. financial asset returns and housing returns are almost disconnected to the Hong Kong counterparts. This seems to be very counter-intuitive, as Hong Kong currency is linked to the U.S. dollars and given the large volume of goods and service trade between Hong Kong and U.S. On the other hand, our Hierarchical Markov Regime Switching VAR model (HMRS-VAR) suggests that unexpected change in U.S. stock return will have a significant impact to the H.K. asset returns as well as GDP. As a whole, the model which includes the U.S. term spread can provide the best in-sample one-quarter-ahead forecast in both H.K. asset returns and GDP. Our HMRS-VAR further suggests that it is during the "normal times" that the U.S. has a larger impact on Hong Kong.

Clearly, there are much room for improvement. Methodologically, for instance, future research can consider to introduce the "China factor," time-varying transition probability, time-varying variance-covariance structure, etc. into the empirical model. ${ }^{24}$ Future research can also employ H.K. data to test among competing theories. ${ }^{25}$ Those research efforts would definitely enrich our understanding of the international linkages of the asset markets.

\footnotetext{
${ }^{24}$ Among others, see Bai and Wang (2011), Engle (2009), Filardo (1994), He et al (2009), for related studies.

${ }^{25}$ For instance, one can test whether the conventional "rational models" or the behavioral models" will gain support from the H.K. data. Among others, see Leung and Tsang (2011a, b) for related studies.
} 


\section{References}

[1] Bai, J. and P. Wang, 2011, Restricted Markov Switching Model and Its Application in Economic Time Series Analysis, forthcoming in Journal of Applied Econometrics.

[2] Benigno, P., 2002. A Simple Approach to International Monetary Policy Coordination. Journal of International Economics, 57, 177-196.

[3] Benigno, G., Benigno, P., 2006. Designing Targeting Rules for International Monetary Policy Cooperation. Journal of Monetary Economics, 53, 473-506.

[4] Bernanke, B., 2007, Globalization and Monetary Policy, available at http://www.federalreserve.gov/newsevents/speech/Bernanke20070302a.htm.

[5] Brunnermeier, M. K., Pedersen, L,H., 2009. Market Liquidity and Funding Liquidity. Review of Financial Studies 22(6), 2201-2238.

[6] Canzoneri, M. B., Cumby, R. E., Diba, B. T., 2005. The Need for International Policy Coordination: What's Old, What's New, What's Yet to Come. Journal of International Economics, 66, 363-384.

[7] Chang, K. L.; N. K. Chen and C. K. Y. Leung, 2010, Would some model please give me some hints? In search of some stylized facts of the Monetary Policy and Asset Return Dynamics, National Taiwan University, mimeo.

[8] Chang, K. L.; N. K. Chen and C. K. Y. Leung, 2011a, Monetary Policy, Term Structure and Real Estate Return: Comparing REIT, housing and stock, Journal of Real Estate Finance and Economics, 43, 221-257.

[9] Chang, K. L.; N. K. Chen and C. K. Y. Leung, 2011b, The Dynamics of Housing Returns in Singapore: How Important are the International Transmission Mechanisms?, forthcoming in Regional Science and Urban Economics.

[10] Chen, N. K. and C. K. Y. Leung, 2008, Asset price spillover, collateral and crises: with an application to property market policy, Journal of Real Estate Finance and Economics, 37, 351-385.

[11] Cheng, L., B. Lin and Z. Zeng, 2010, Housing in a Neoclassical Growth Model, Pacific Economic Review, 15, 246-262.

[12] Chong, T. T. L., T. H. Lam and I. K. M. Yan, 2011, Is the Chinese Stock Market Really Inefficient, City University of Hong Kong, mimeo.

[13] Chong, T. T. L., and I. K. M. Yan, 2011, Threshold Models with Multiple Threshold Variables and the Prediction of Financial Crises, City University of Hong Kong, mimeo.

[14] Chou, W. L. and K. Y. Wong, 2001, Economic growth and international trade: the case of Hong Kong, Pacific Economic Review, 6, 313-329.

[15] Corsetti, G., Pesenti, P., 2001. Welfare and Macroeconomic Interdependence. Quarterly Journal of Economics, 116, 421-45. 
[16] Corsetti, G., Pesenti, P., 2005. International Dimensions of Optimal Monetary Policy. Journal of Monetary Economics, 52(2), 281-305.

[17] Corsetti, G., Pesenti, P., Roubini, N., 1999. What Cause the Asian currency and financial crisis? Japan and the World Economy 11, 305-73.

[18] Cosslett, S. and L. F. Lee, 1985, Serial correlation in latent discrete variable models, Journal of Econometrics, 27, 79-97.

[19] Davis, S., 2010, The Adverse Feedback Loop and the Real Effects of Financial Sector Uncertainty, Vanderbilt University, mimeo.

[20] Demyanyk, Y.S., Van Hemert, O., 2009. Understanding the Subprime Mortgage Crisis. Forthcoming in Review of Financial Studies.

[21] Diebold, F. and R. Mariano, 1995, Comparing predictive accuracy, Journal of Business \& Economic Statistics, 13, 253-263.

[22] Engle, R., 2009, Anticipating correlations: a new paradigm for risk management, Princeton: Princeton University Press.

[23] Estrella, A., 2005, Why does the yield curve predict output and inflation?, Economic Journal 115, 722-44.

[24] Estrella, A. and G. Hardouvelis, 1991, The term structure as a predictor of real economic activity, Journal of Finance 46, 555-76.

[25] Estrella, A. and F. Mishkin, 1997, The predictive power of the term structure of interest rates in Europe and the United States: implications for the European Central Bank, European Economic Review 41, 1375-1401.

[26] Estrella, A. and M. R. Trubin, 2006, The yield curve as a leading indicator: some practical issues, Current Issues in Economics and Finance 12, Federal Reserve Bank of New York.

[27] Filardo, A., 1994, Business-Cycle Phases and Their Transitional Dynamics, Journal of Business \& Economic Statistics, 12, 299-308.

[28] Garcia, R. and H. Schaller, 2002, Are the effects of monetary policy asymmetric, Economic Inquiry, 40, 102-119.

[29] Gertler, M. and N. Kiyotaki, 2010, Financial intermediation and credit policy in business cycle analysis, forthcoming in Handbook of Monetary Economics, vol. 3, edited by M. Woodford, New York: Elsevier.

[30] Gorton, G.B., 2007. The Panic of 2007. Working paper.

[31] Hamilton, J., 1994, Time series analysis, Princeton: Princeton University Press.

[32] He, D., Z. Zhang and H. Wang, 2009, Hong Kong's financial market interactions with the US and Mainland China in crisis and tranquil times, Hong Kong Monetary Authority, mimeo. 
[33] Ho, L. S. and G. Wong, 2008, Nexus between housing and the macroeconomy: the Hong Kong case, Pacific Economic Review, 13, 223-239.

[34] Kaminsky, G.L., Reinhart, C.M., 2000. On Crises, Contagion, and Confusion. Journal of International Economics 51, 145-168.

[35] Leung, C. K. Y., 2003, Economic Growth and Increasing House Prices, Pacific Economic Review, 8, 183-90.

[36] Leung, C. K. Y., 2007, Equilibrium correlations of asset price and return," Journal of Real Estate Finance and Economics 34, 233-256.

[37] Leung, C. K. Y., P. W. Y. Cheung and E. C. H. Tang, 2011, Financial Crisis and the Co-movements of Housing Sub-markets: Do relationships change after a crisis?, forthcoming in International Real Estate Review.

[38] Leung, C. K. Y. and E. C. H. Tang, 2011, Comparing two financial crises: the case of Hong Kong Real Estate Markets, forthcoming in "Global Housing Markets: Crises, Institutions and Policies," eds. by Ashok Bardhan, Robert Edelstein and Cynthia Kroll, John Wiley \& Sons.

[39] Leung, C. K. Y. and W. L. Teo, 2009, The Wall Street concerns might be right: equilibrium correlations of asset price do change with monetary policy, paper presented at the Asian Real Estate Society meeting.

[40] Leung, T. C. and K. P. Tsang, 2011a, Anchoring and Loss Aversion in the Housing Market: Implications on Price Dynamics, Chinese University of Hong Kong, mimeo.

[41] Leung, T. C. and K. P. Tsang, 2011b, Can Anchoring and Loss Aversion Explain the Predictability in the Housing Market? forthcoming in the Pacific Economic Review.

[42] Lubik, T., and F. Schorfheide, 2003, Computing sunspot equilibria in linear rational expectations models, Journal of Economic Dynamics \& Control 28, 273-285.

[43] Lubik, T., and F. Schorfheide, 2005, A Bayesian Look at New Open Economy Macroeconomics, NBER Macroeconomics Annual, 313-366.

[44] Maheu, J. and T. McCurdy, 2000, Identifying bull and bear markets in stock returns. Journal of Business and Economic Statistics, 18, 100-112.

[45] Obstfeld, M., Rogoff, K., 2002. Global Implications of Self-Oriented National Monetary Policy Rules. Quarterly Journal of Economics, 117, 503-535.

[46] Peek, J., Rosengren, E.S., 2000. Collateral Damage: Effects of the Japanese Bank Crisis on Real Activity in the United States. American Economic Review 90, 30-45.

[47] Plosser, C. and K. G. Rouwenhorst, 1994, International term structures and real economic growth, Journal of Monetary Economics 33, 133-155.

[48] Radelet, S., Sachs, J., 1998. The East Asian Financial Crisis: Diagnosis, Remedies, Prospects. Brookings Papers on Economic Activity, 1-74.

[49] Sims, C., 1980, Macroeconomics and reality, Econometrica, 48, 1-48. 
[50] Stock, J., and M. Watson, 1989, New Indexes of Coincident and Leading Indicators, In NBER Macroeconomic Annual 4, ed. Olivier Blanchard and Stanley Fischer, 351394.

[51] Stock, J. and M. Watson, 2002, Forecasting Using Principal Components From a Large Number of Predictors, Journal of American Statistical Association, 97(260), 1167-1179.

[52] Taylor, J., 2009. The Financial Crisis and the Policy Responses: An Empirical Analysis of What Went Wrong. Working paper.

[53] U.S. Congress (Joint Economic Committee), 2000, International dimensions to U.S. monetary policy, available at http://www.house.gov/jec/fed/intern.pdf. 

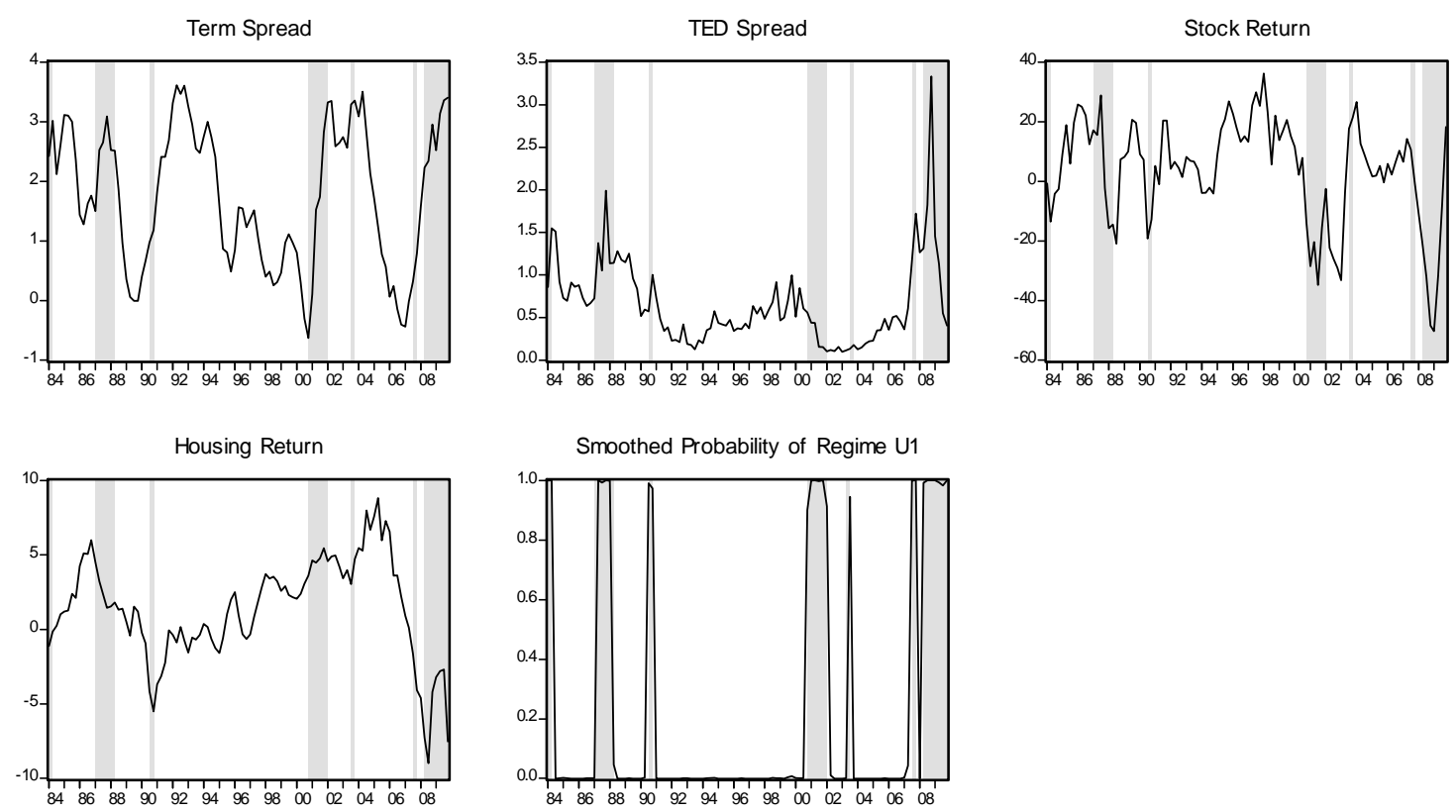

Figure 1 The Data of US and the smoothed probabilities of regime U1 Note: Shaded areas indicate the periods of regime U1
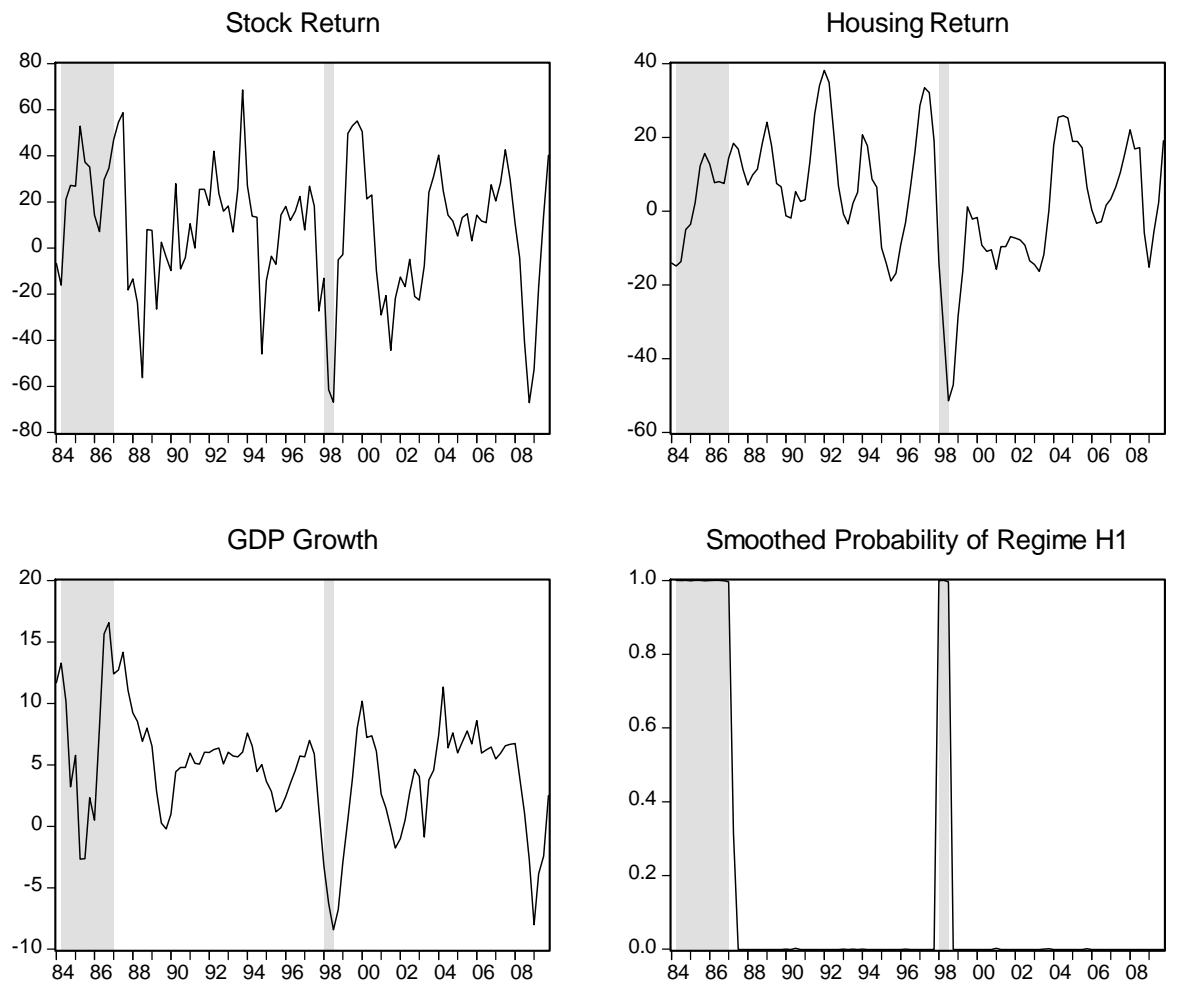

Figure 2 The data for Hong Kong and the smoothed probabilities of regime H1 for Model B (Shaded areas indicate the periods of regime H1) 
Figure 3 Responses of (Stock return, Housing return, GDP growth) for one standard deviation increase in unexpected term spread
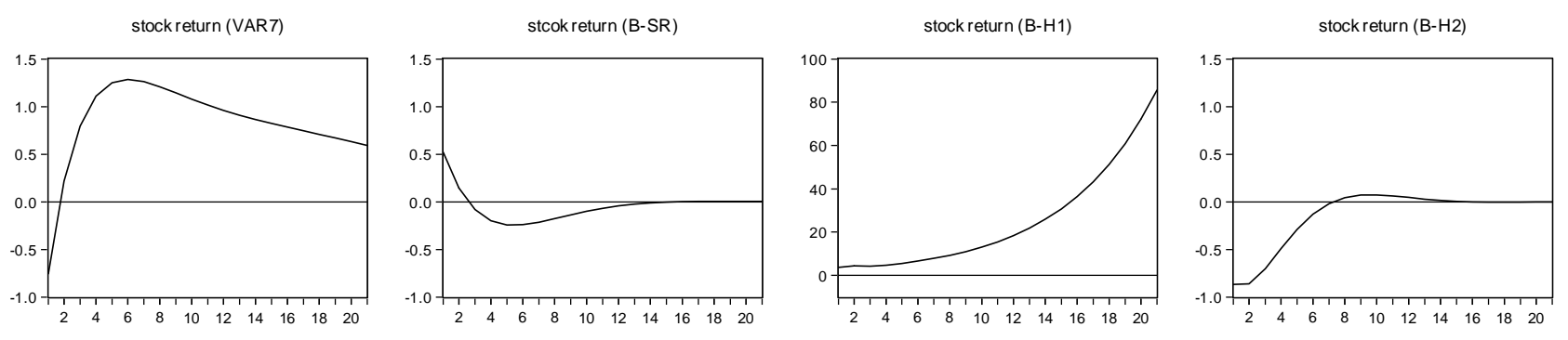

housing return (VAR7)

housing return (B-SR)
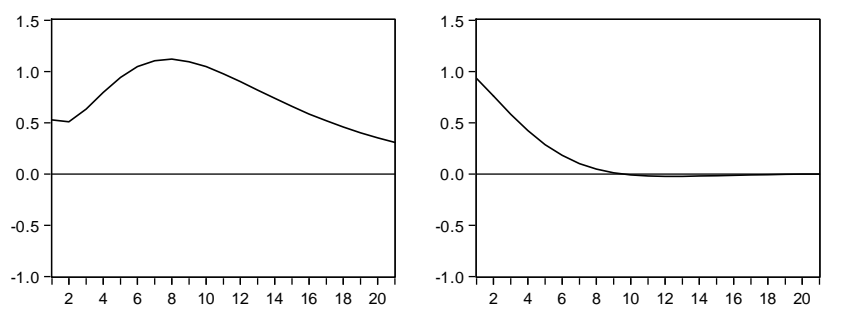

housing return (B-H1)

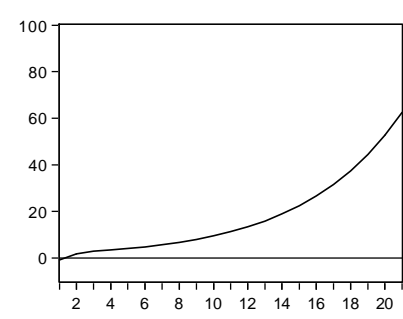

housing return (B-H2)

gdp growth (VAR7)

gdp growth (B-SR)
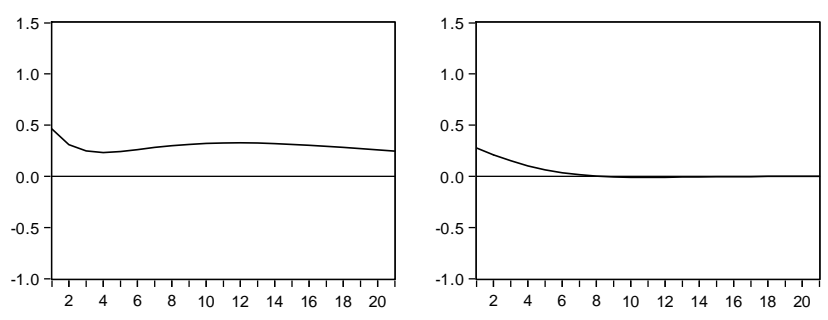

gdp growth (B-H1)

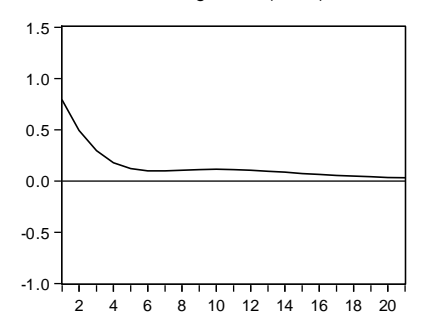

gdp growth (B-H2)
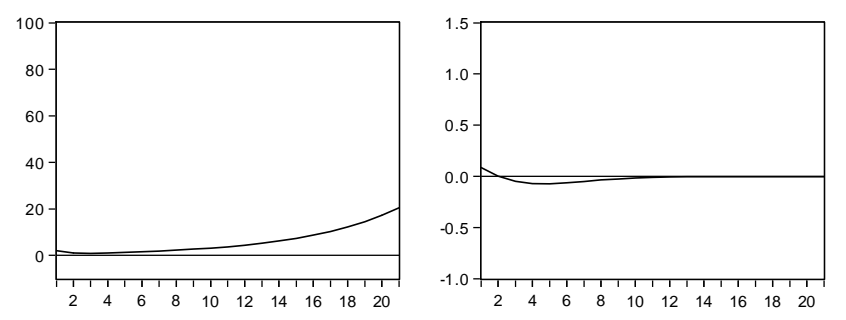

Note: “VAR7” refers to the restricted VAR(7) model. "B-SR” refers to model B with single regime restriction. "B-H1” refers to the model B under regime H1. "B-H2” refers to the model B under regime H2. 
Figure 4 Responses of (Stock return, Housing return, GDP growth) for one standard deviation increase in unexpected TED spread
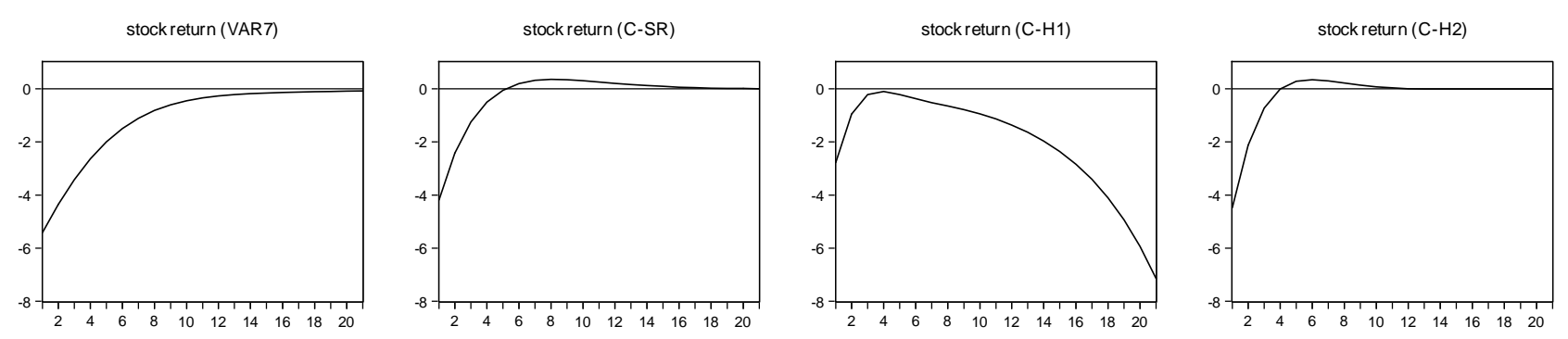

housing return (VAR7)

housing return (C-SR)
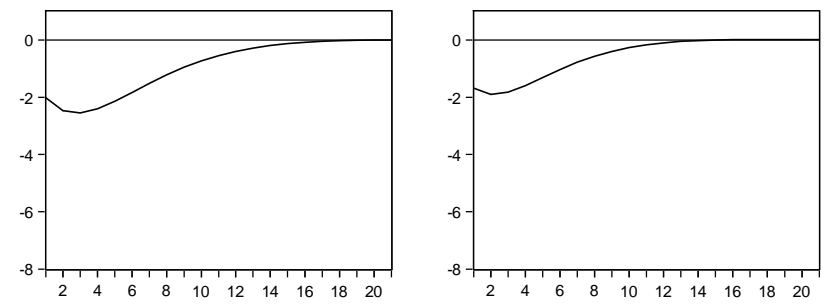

housing return (C-H1)

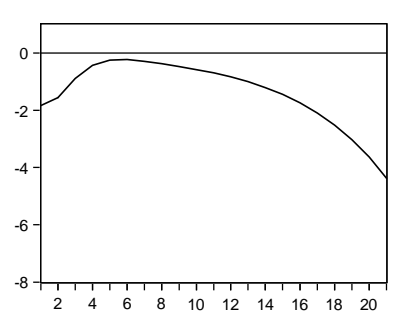

housing return (C-H2)

gdp growth (VAR7)

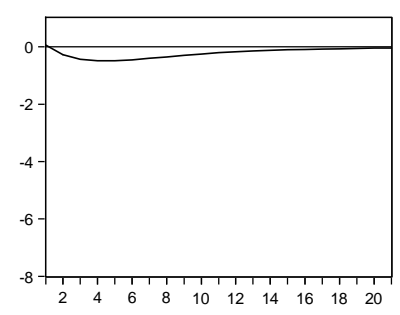

gdp growth (C-SR)

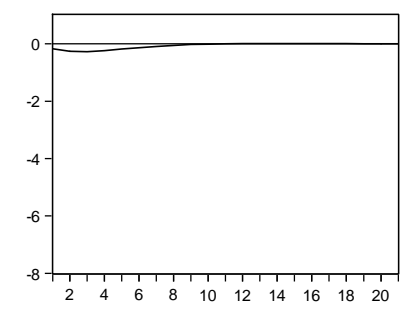

gdp growth (C-H1)

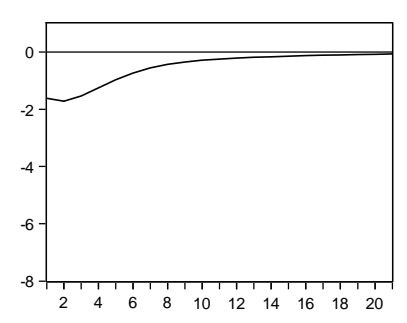

gdp growth (C-H2)
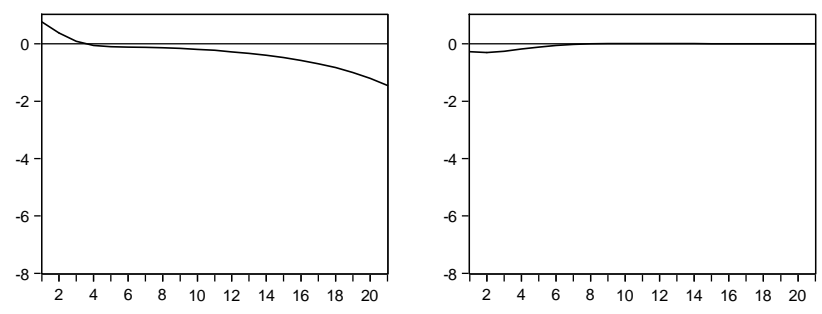

Note: “VAR7” refers to the restricted VAR(7) model. "C-SR” refers to model C with single regime restriction. "C-H1” refers to the model C under regime H1. “C-H2” refers to the model C under regime H2. 
Figure 5 Responses of (Stock return, Housing return, GDP growth) for one standard deviation increase in unexpected stock return
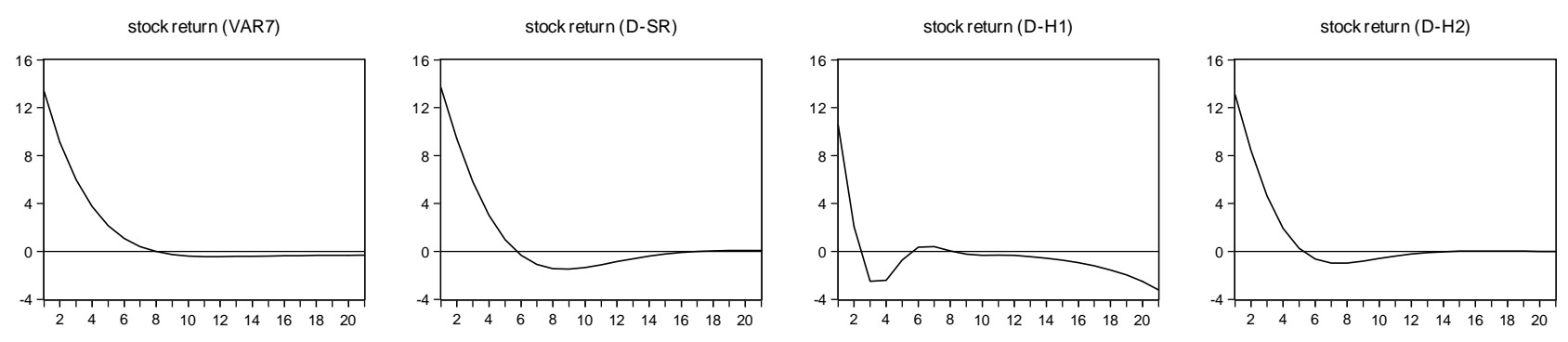

housing return (VAR7)

housing return (D-SR)
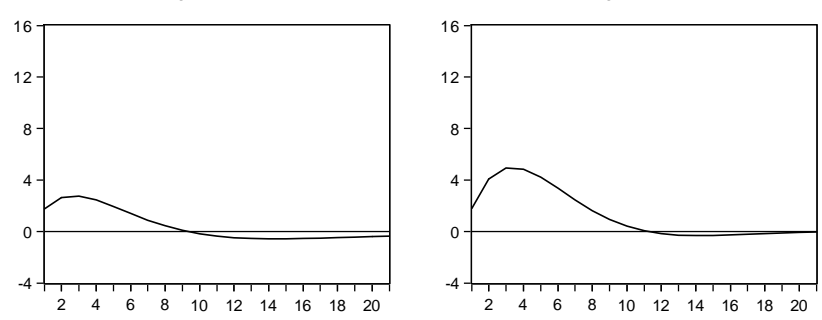

housing return (D-H1)

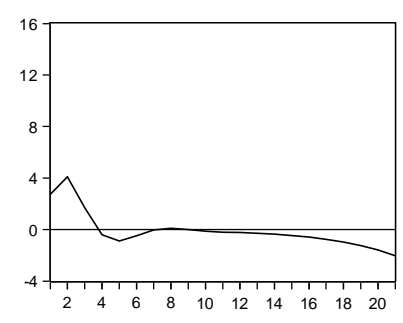

housing return (D-H2)

gdp growth (VAR7)
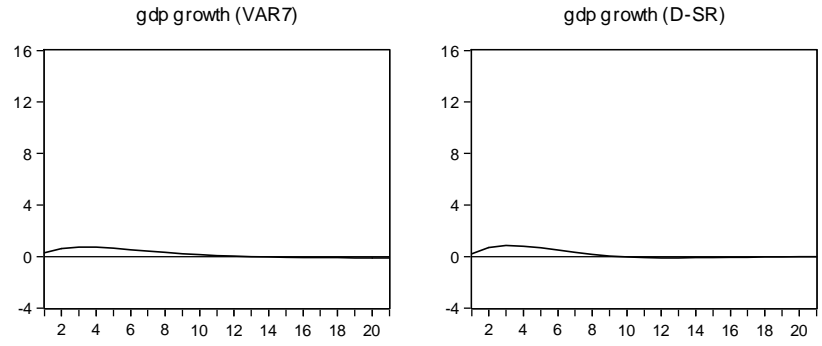

gdp growth (D-H1)

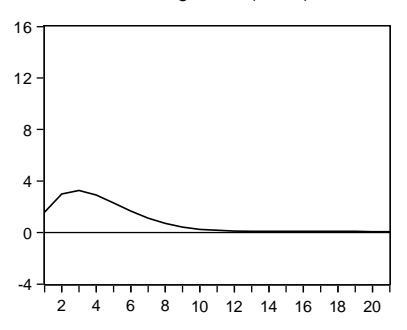

gdp growth (D-H2)
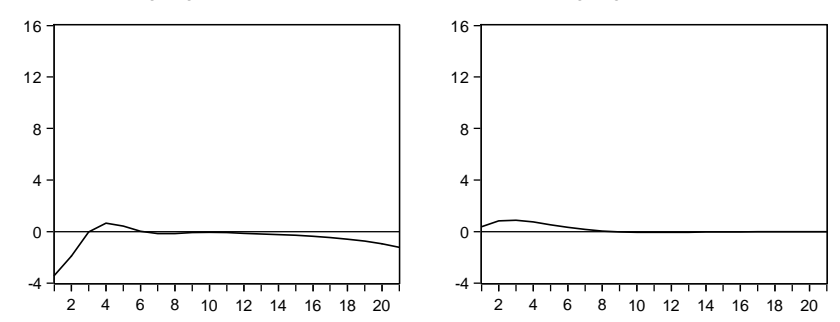

Note: "VAR7” refers to the restricted VAR(7) model. "D-SR" refers to model D with single regime restriction. "D-H1” refers to the model D under regime H1. “D-H2” refers to the model D under regime H2. 
Figure 6 Responses of (Stock return, Housing return, GDP growth) for one standard deviation increase in unexpected housing return

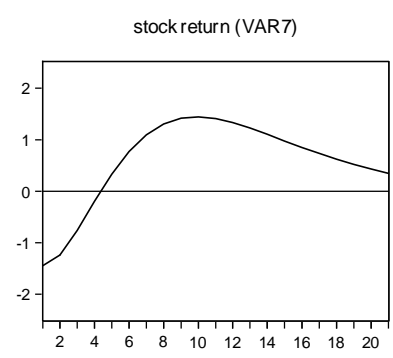

housing return (VAR7)

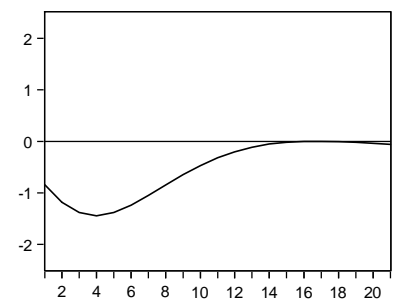

gdp growth (VAR7)

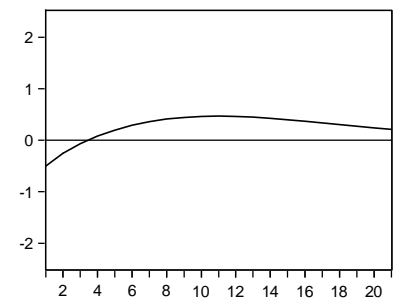

stock return (E-SR)

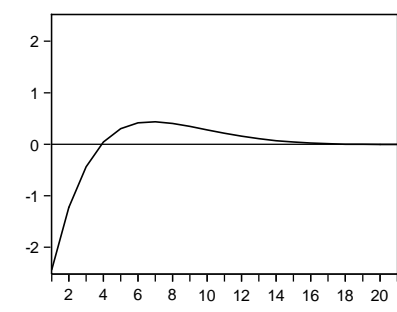

housing return (E-SR)

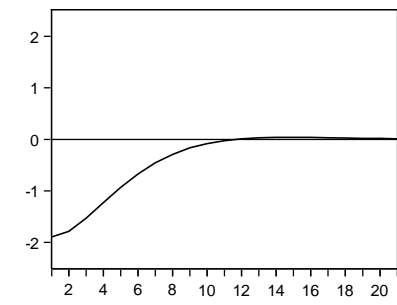

gdp growth (E-SR)

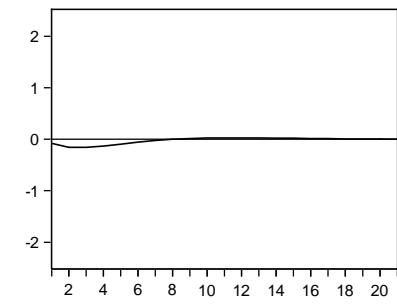

stock return (E-H1)

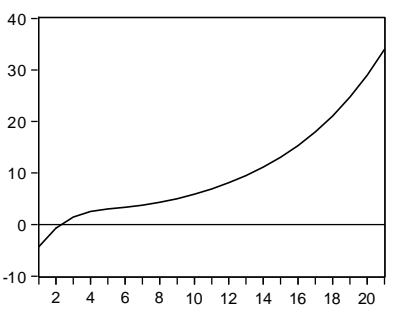

housing return (E-H1)

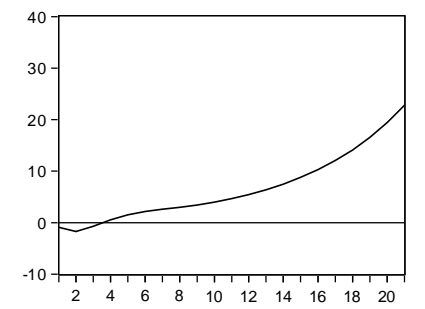

gdp growth (E-H1)

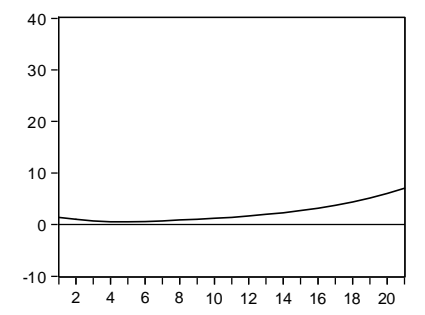

stock return (E-H2)

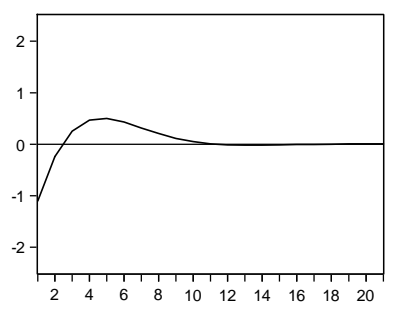

housing return (E-H2)

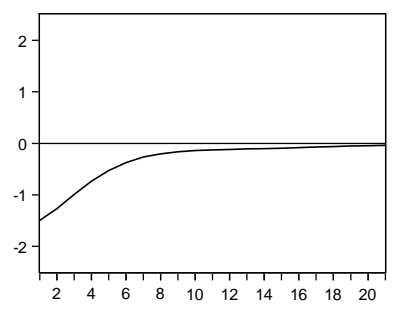

gdp growth (E-H2)

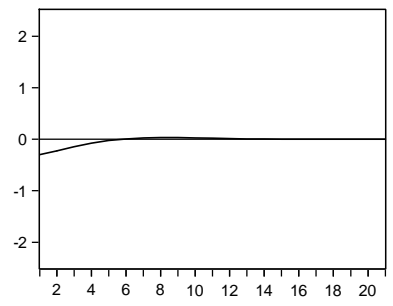

Note: "VAR7" refers to the restricted VAR(7) model. "E-SR" refers to model E with single regime restriction. "E-H1" refers to the model E under regime H1. "E-H2” refers to the model E under regime H2. 
Table 1 Model Specification

\begin{tabular}{|c|l|}
\hline Model & Specification \\
\hline A & Stock Return, Housing Return, GDP Growth \\
\hline B & $\begin{array}{l}\text { Stock Return, Housing Return, GDP Growth + Expected and Unexpected } \\
\text { Term Spread (USA) }\end{array}$ \\
\hline D & $\begin{array}{l}\text { Stock Return, Housing Return, GDP Growth + Expected and Unexpected } \\
\text { TED Spread (USA) }\end{array}$ \\
\hline E & $\begin{array}{l}\text { Stock Return (USA) } \\
\text { Housing Return (USA) }\end{array}$ \\
\hline $\begin{array}{c}\text { Linear VAR } \\
\text { (VAR(7)_1) }\end{array}$ & $\begin{array}{l}\text { term spread (US), TED spread (US), stock returns (US), housing returns } \\
\text { (US), stock returns (HK), housing returns (HK), GDP growth (HK). }\end{array}$ \\
\hline $\begin{array}{c}\text { Linear VAR } \\
\text { (VAR(7)_2) }\end{array}$ & $\begin{array}{l}\text { term spread (US), TED spread (US), stock returns (US), housing returns } \\
\text { (US), stock returns (HK), GDP growth (HK), housing returns (HK) }\end{array}$ \\
\hline Restricted & $\begin{array}{l}\text { term spread (US), TED spread (US), stock returns (US), housing returns } \\
\text { (US), stock returns (HK), housing returns (HK), GDP growth (HK) (with } \\
\text { VAR } \\
\text { (VAR(7)_R) }\end{array}$ \\
\hline
\end{tabular}

Table 2 Summary Statistics for US and HK data (1984Q1-2009Q4) (only standard deviations are reported)

\begin{tabular}{|c|c|c|}
\hline & U.S. variables & H.K. variables \\
\hline Stock Return & 17.519 & 28.126 \\
\hline Housing Return & 3.373 & 16.471 \\
\hline Term Spread & 1.173 & $/$ \\
\hline TED Spread & 0.497 & $/$ \\
\hline GDP growth & $/$ & 4.691 \\
\hline
\end{tabular}


Table 3 Identification of Regimes for HK Under Different Models

\begin{tabular}{|c|ll|}
\hline Model & \multicolumn{2}{|l|}{ Periods Identified to be Regime HK1 } \\
\hline A & 1984Q2-1987Q2 & 1998Q1-1998Q3 \\
\hline B & 1984Q2-1987Q1 & 1998Q1-1998Q3 \\
\hline C & 1984Q2-1987Q3 & 1998Q1-1998Q3 \\
& 2002Q3-2003Q2 \\
\hline D & 1984Q2-1987Q1 & 1998Q1-1998Q3 \\
\hline E & 1984Q2-1987Q2 & 1992Q3-1993Q1 \\
& 1998Q1-1998Q3 & \\
\hline
\end{tabular}

Table 4 AICs Under Different Model Specifications

\begin{tabular}{|c|c|c|c|c|}
\hline \multirow{2}{*}{ Model } & \multicolumn{2}{|c|}{ USA under single regime } & \multicolumn{2}{c|}{ USA under regime switching } \\
\cline { 2 - 5 } & Single-Regime & Regime Switching & Single-Regime & Regime Switching \\
\hline A & 20.599 & 19.971 & 20.599 & 19.971 \\
\hline B & 20.654 & 19.823 & 20.666 & 19.878 \\
\hline C & 20.591 & 20.011 & 20.627 & 20.054 \\
\hline D & 20.019 & 19.491 & 20.074 & 19.514 \\
\hline E & 20.626 & 20.007 & 20.608 & 20.028 \\
\hline
\end{tabular}


Table 5 The Impacts of Expected and Unexpected US Financial and Housing Markets on HK Economy

\begin{tabular}{|c|c|c|c|c|c|c|c|c|c|c|}
\hline \multirow{2}{*}{\multicolumn{2}{|c|}{ USA Variables }} & \multicolumn{3}{|c|}{$\begin{array}{l}\text { Stock Return } \\
\text { (see parameters } \gamma_{z 1} \text { and } \gamma_{u 1} \text { ) }\end{array}$} & \multicolumn{3}{|c|}{$\begin{array}{l}\text { Housing Return } \\
\text { (see parameters } \gamma_{z 2} \text { and } \gamma_{u 2} \text { ) }\end{array}$} & \multicolumn{3}{|c|}{ GDP Growth } \\
\hline & & \multirow{2}{*}{$\begin{array}{c}\text { Single } \\
\text { regime }\end{array}$} & \multirow{2}{*}{$\begin{array}{c}\text { regime } \\
\text { HK1 } \\
\text { No } \\
(16.190) \\
\end{array}$} & \multirow{2}{*}{$\begin{array}{c}\text { regime } \\
\text { HK2 } \\
\text { No } \\
(0.284) \\
\end{array}$} & \multirow{2}{*}{\begin{tabular}{|c}
$\begin{array}{c}\text { single } \\
\text { regime }\end{array}$ \\
$\begin{array}{c}\text { No } \\
(1.042)\end{array}$ \\
\end{tabular}} & \multirow{2}{*}{$\begin{array}{c}\text { regime } \\
\text { HK1 } \\
\text { No } \\
(1.381) \\
\end{array}$} & \multirow{2}{*}{$\begin{array}{c}\text { regime } \\
\text { HK2 } \\
\text { No } \\
(0.493) \\
\end{array}$} & \multirow{2}{*}{$\begin{array}{c}\begin{array}{c}\text { single } \\
\text { regime }\end{array} \\
\text { No } \\
(0.115) \\
\end{array}$} & \multirow{2}{*}{$\begin{array}{c}\text { regime } \\
\text { HK1 } \\
\text { No } \\
(1.566) \\
\end{array}$} & \multirow{2}{*}{$\begin{array}{c}\text { regime } \\
\text { HK2 } \\
\text { No } \\
(0.234) \\
\end{array}$} \\
\hline Term Spread & $Z_{t-1}$ & & & & & & & & & \\
\hline & $\widehat{u}_{t}$ & $\begin{array}{c}\text { No } \\
(1.400) \\
\end{array}$ & $\begin{array}{c}\text { No } \\
(9.838) \\
\end{array}$ & $\begin{array}{c}\text { No } \\
(-2.335) \\
\end{array}$ & $\begin{array}{c}\text { No } \\
(2.504)\end{array}$ & $\begin{array}{c}\text { No } \\
(-2.289) \\
\end{array}$ & $\begin{array}{c}\text { No } \\
(2.118) \\
\end{array}$ & $\begin{array}{c}\text { No } \\
(0.746) \\
\end{array}$ & $\begin{array}{c}\text { No } \\
(5.216) \\
\end{array}$ & $\begin{array}{c}\text { No } \\
(0.230)\end{array}$ \\
\hline \multirow[t]{2}{*}{ TED spread } & $Z_{t-1}$ & $\begin{array}{c}\text { No } \\
(-4.679) \\
\end{array}$ & $\begin{array}{c}\text { No } \\
(7.311) \\
\end{array}$ & $\begin{array}{c}\text { No } \\
(-11.911) \\
\end{array}$ & $\begin{array}{c}\text { No } \\
(0.093) \\
\end{array}$ & $\begin{array}{c}\text { No } \\
(-3.945) \\
\end{array}$ & $\begin{array}{c}\text { No } \\
(-1.121) \\
\end{array}$ & $\begin{array}{c}\text { No } \\
(-0.687) \\
\end{array}$ & $\begin{array}{c}\text { No } \\
(0.214)\end{array}$ & $\begin{array}{c}\text { Yes } \\
(-0.954 * *)\end{array}$ \\
\hline & $\widehat{u}_{t}$ & $\begin{array}{c}\text { Yes } \\
(-16.886 * *) \\
\end{array}$ & $\begin{array}{c}\text { No } \\
(-11.222) \\
\end{array}$ & $\begin{array}{c}\text { Yes } \\
\left(-18.088^{*}\right) \\
\end{array}$ & $\begin{array}{c}\text { Yes } \\
(-6.795 *) \\
\end{array}$ & $\begin{array}{c}\text { No } \\
(-7.418) \\
\end{array}$ & $\begin{array}{c}\text { Yes } \\
(-6.526 *) \\
\end{array}$ & $\begin{array}{c}\text { No } \\
(-0.670) \\
\end{array}$ & $\begin{array}{c}\text { No } \\
(3.119) \\
\end{array}$ & $\begin{array}{c}\text { No } \\
(-1.083) \\
\end{array}$ \\
\hline \multirow[t]{2}{*}{ Stock return } & $Z_{t-1}$ & $\begin{array}{c}\text { No } \\
(0.006) \\
\end{array}$ & $\begin{array}{c}\text { No } \\
(-0.317) \\
\end{array}$ & $\begin{array}{c}\text { No } \\
(0.179) \\
\end{array}$ & $\begin{array}{c}\text { Yes } \\
(-0.128 * *)\end{array}$ & $\begin{array}{c}\text { No } \\
(0.022) \\
\end{array}$ & $\begin{array}{c}\text { No } \\
(-0.006) \\
\end{array}$ & $\begin{array}{c}\text { No } \\
(0.000) \\
\end{array}$ & $\begin{array}{c}\text { No } \\
(-0.129) \\
\end{array}$ & $\begin{array}{c}\text { No } \\
(0.003)\end{array}$ \\
\hline & $\widehat{u}_{t}$ & $\begin{array}{c}\text { Yes } \\
\left(1.496^{* * *}\right)\end{array}$ & $\begin{array}{c}\text { No } \\
(1.156) \\
\end{array}$ & $\begin{array}{c}\text { Yes } \\
\left(1.434^{* * *}\right)\end{array}$ & $\begin{array}{c}\text { Yes } \\
\left(0.196^{* *}\right)\end{array}$ & $\begin{array}{c}\text { No } \\
(0.299) \\
\end{array}$ & $\begin{array}{c}\text { Yes } \\
\left(0.174^{*}\right) \\
\end{array}$ & $\begin{array}{c}\text { No } \\
(0.025) \\
\end{array}$ & $\begin{array}{c}\text { No } \\
(-0.372) \\
\end{array}$ & $\begin{array}{c}\text { Yes } \\
(0.042 *) \\
\end{array}$ \\
\hline \multirow[t]{2}{*}{ Housing return } & $Z_{t-1}$ & $\begin{array}{c}\text { No } \\
(0.324) \\
\end{array}$ & $\begin{array}{c}\text { No } \\
(-0.140)\end{array}$ & $\begin{array}{c}\text { No } \\
(0.660) \\
\end{array}$ & $\begin{array}{c}\text { No } \\
(-0.239)\end{array}$ & $\begin{array}{c}\text { No } \\
(0.714) \\
\end{array}$ & $\begin{array}{c}\text { No } \\
(-0.058)\end{array}$ & $\begin{array}{c}\text { No } \\
(0.124) \\
\end{array}$ & $\begin{array}{c}\text { No } \\
(0.279) \\
\end{array}$ & $\begin{array}{c}\text { No } \\
(0.114)\end{array}$ \\
\hline & $\widehat{u}_{t}$ & $\begin{array}{c}\text { No } \\
(-2.171)\end{array}$ & $\begin{array}{c}\text { No } \\
(-3.838)\end{array}$ & $\begin{array}{c}\text { No } \\
(-0.980)\end{array}$ & $\begin{array}{c}\text { Yes } \\
\left(-1.688^{* *}\right)\end{array}$ & $\begin{array}{c}\text { No } \\
(-0.820)\end{array}$ & $\begin{array}{c}\text { Yes } \\
(-1.336 *)\end{array}$ & $\begin{array}{c}\text { No } \\
(-0.076)\end{array}$ & $\begin{array}{c}\text { No } \\
(1.263)\end{array}$ & $\begin{array}{c}\text { No } \\
(-0.264)\end{array}$ \\
\hline
\end{tabular}

Note: Values in parentheses are parameter estimates. 
Table 6a In-sample one-step-ahead predictions on HK Stock Return under different model specifications (Assume that US model is regime-switching)

\begin{tabular}{|c|c|c|c|c|}
\hline \multirow{2}{*}{ Model } & \multicolumn{2}{|c|}{ MAE } & \multicolumn{2}{c|}{ RMSE } \\
\cline { 2 - 5 } & Singe-Regime & Regime Switching & Singe-Regime & Regime Switching \\
\hline A & 15.5610 & 14.8088 & 20.9376 & 21.0821 \\
\hline B & 15.4734 & $\mathbf{1 4 . 5 1 6 7}$ & 20.8072 & $\mathbf{2 0 . 5 0 8 5}$ \\
\hline C & 16.2750 & 15.5045 & 21.2916 & 21.6919 \\
\hline D & 19.7363 & 18.3100 & 26.2061 & 24.7653 \\
\hline E & 15.8788 & 14.7920 & 21.0845 & $\mathbf{2 0 . 3 5 9 9}$ \\
\hline $\begin{array}{c}\text { Linear VAR } \\
\text { (VAR(7)_1) }\end{array}$ & 15.3537 & $/$ & 20.7185 & $/$ \\
\hline $\begin{array}{c}\text { Linear VAR } \\
\text { (VAR(7)_2) }\end{array}$ & 15.3540 & $/$ & 20.7185 & $/$ \\
\hline $\begin{array}{c}\text { Restricted VAR } \\
\text { (VAR(7)_R) }\end{array}$ & 15.3312 & $/$ & 20.9177 & $/$ \\
\hline
\end{tabular}

Table 6b In-sample one-step-ahead predictions on HK Housing Return under different model specifications (Assume that US model is regime-switching)

\begin{tabular}{|c|c|c|c|c|}
\hline \multirow{2}{*}{ Model } & \multicolumn{2}{|c|}{ MAE } & \multicolumn{2}{c|}{ RMSE } \\
\cline { 2 - 5 } & Singe-Regime & Regime Switching & Singe-Regime & Regime Switching \\
\hline A & 5.6555 & 5.5301 & 7.4881 & 7.2625 \\
\hline B & 5.6510 & 5.4592 & 7.3703 & 7.1103 \\
\hline C & 5.8173 & 5.6473 & 7.5305 & 7.2955 \\
\hline D & 5.8450 & 5.5956 & 7.5364 & 7.4099 \\
\hline E & 5.9623 & 5.6849 & 7.6768 & 7.3289 \\
\hline $\begin{array}{c}\text { Linear VAR } \\
\text { (VAR(7)_1) }\end{array}$ & 5.6509 & $/$ & 7.2144 & $/$ \\
\hline $\begin{array}{c}\text { Linear VAR } \\
\text { (VAR(7)_2) }\end{array}$ & 5.6509 & $/$ & 7.2144 & $/$ \\
\hline $\begin{array}{c}\text { Restricted VAR } \\
\text { (VAR(7)_R) }\end{array}$ & 5.6995 & $/$ & 7.2495 & $/$ \\
\hline
\end{tabular}

Table 6c In-sample one-step-ahead predictions on HK GDP Growth under different model specifications (Assume that US model is regime-switching)

\begin{tabular}{|c|c|c|c|c|}
\hline \multirow{2}{*}{ Model } & \multicolumn{2}{|c|}{ MAE } & \multicolumn{2}{c|}{ RMSE } \\
\cline { 2 - 5 } & Singe-Regime & Regime Switching & Singe-Regime & Regime Switching \\
\hline A & 1.6936 & 1.6357 & 2.3893 & 2.2737 \\
\hline B & 1.6603 & 1.5545 & 2.4057 & 2.3722 \\
\hline C & 1.6946 & 1.6515 & 2.3756 & 2.3151 \\
\hline D & 1.7368 & 1.8090 & 2.4064 & 2.5087 \\
\hline E & 1.6705 & 1.6478 & 2.3486 & 2.2114 \\
\hline $\begin{array}{c}\text { Linear VAR } \\
\text { (VAR(7)_1) }\end{array}$ & 1.6593 & $/$ & 2.3351 & $/$ \\
\hline $\begin{array}{c}\text { Linear VAR } \\
\text { (VAR(7)_2) }\end{array}$ & 1.6593 & $/$ & 2.3351 & $/$ \\
\hline $\begin{array}{c}\text { Restricted VAR } \\
\text { (VAR(7)_R) }\end{array}$ & 1.6769 & $/$ & 2.3426 & $/$ \\
\hline
\end{tabular}


Table 7a Diebold and Mariano (1995) Statistics for HK Stock Return (Model B with regime switching as the benchmark)

\begin{tabular}{|c|c|c|c|c|}
\hline Model & \multicolumn{2}{|c|}{ MAE } & \multicolumn{2}{c|}{ MSE } \\
\hline A & Singe-Regime & Regime Switching & Singe-Regime & Regime Switching \\
\hline B & -1.2238 & -0.6469 & -0.2537 & -0.6277 \\
\hline C & -1.1538 & $/$ & -0.1789 & $/$ \\
\hline D & $-1.8954^{*}$ & -1.3788 & -0.4638 & -0.9036 \\
\hline E & $-4.0152^{* * *}$ & $-3.4486^{* * *}$ & $-2.4884^{* *}$ & $-2.7355^{* * *}$ \\
\hline $\begin{array}{c}\text { Linear VAR } \\
\text { (VAR(7)_1) }\end{array}$ & -1.5264 & -0.5716 & -0.3407 & 0.1858 \\
\hline $\begin{array}{c}\text { Linear VAR } \\
\text { (VAR(7)_2) }\end{array}$ & -0.9259 & $/$ & -0.1203 & $/$ \\
\hline $\begin{array}{c}\text { Restricted VAR } \\
\text { (VAR(7)_R) }\end{array}$ & -0.9631 & $/$ & -0.1203 & $/$ \\
\hline
\end{tabular}

Note: * Significant at $10 \%$ level of significance;** Significant at $5 \%$ level of significance; *** Significant at $1 \%$ level of significance.

Table 7b Diebold and Mariano (1995) statistics for HK Housing Return (Model B with regime switching as the benchmark)

\begin{tabular}{|c|c|c|c|c|}
\hline Model & \multicolumn{2}{|c|}{ MAE } & \multicolumn{2}{c|}{ MSE } \\
\hline A & Singe-Regime & Regime Switching & Singe-Regime & Regime Switching \\
\hline B & -0.6212 & -0.6158 & -0.8723 & -1.1863 \\
\hline C & -0.6542 & $/$ & -0.6372 & $/$ \\
\hline D & -1.1180 & -0.9886 & -0.9612 & -0.8259 \\
\hline E & -1.5657 & -0.6916 & -0.9219 & -1.3988 \\
\hline $\begin{array}{c}\text { Linear VAR } \\
\text { (VAR(7)_1) }\end{array}$ & -0.7213 & -1.1943 & -1.3750 & -1.1057 \\
\hline $\begin{array}{c}\text { Linear VAR } \\
\text { (VAR(7)_2) }\end{array}$ & -0.7214 & $/$ & -0.2778 & $/$ \\
\hline $\begin{array}{c}\text { Restricted VAR } \\
\text { (VAR(7)_R) }\end{array}$ & -0.9172 & $/$ & -0.2778 & $/$ \\
\hline
\end{tabular}

Table 7c Diebold and Mariano (1995) statistics for HK GDP Growth (Model B with regime switching as the benchmark)

\begin{tabular}{|c|c|c|c|c|}
\hline Model & \multicolumn{2}{|c|}{ MAE } & \multicolumn{2}{|c|}{ MSE } \\
\hline & Singe-Regime & Regime Switching & Singe-Regime & Regime Switching \\
\hline A & -1.1908 & -1.1242 & -0.0922 & 0.7306 \\
\hline $\mathrm{B}$ & -0.9594 & 1 & -0.1945 & 1 \\
\hline C & -1.1757 & -1.0488 & -0.0185 & 0.3387 \\
\hline $\mathrm{D}$ & -1.5512 & $-2.5806 * * *$ & -0.1843 & -0.8787 \\
\hline $\mathrm{E}$ & -0.9419 & -0.9401 & 0.1240 & 0.8950 \\
\hline $\begin{array}{l}\text { Linear VAR } \\
\left(\operatorname{VAR}(7) \_1\right)\end{array}$ & -0.8569 & / & 0.1967 & / \\
\hline $\begin{array}{l}\text { Linear VAR } \\
\text { (VAR(7)_2) }\end{array}$ & -0.8570 & / & 0.1967 & / \\
\hline $\begin{array}{c}\text { Restricted VAR } \\
\text { (VAR(7)_R) }\end{array}$ & -0.9689 & / & 0.1554 & / \\
\hline
\end{tabular}




\section{Appendix A: Details of the Regression Results}

Table A1 Summary table for the estimation of the linear VAR models

\begin{tabular}{|c|c|c|c|c|c|c|}
\hline \multirow[b]{2}{*}{ Parameter } & \multicolumn{2}{|c|}{ VAR(7)_1 } & \multicolumn{2}{|c|}{$\operatorname{VAR}(7) \_2$} & \multicolumn{2}{|c|}{ VAR(7)_R } \\
\hline & Estimate & S.E. & Estimate & S.E. & Estimate & S.E. \\
\hline$C_{1}$ & 0.4444 & 0.5960 & 0.4444 & 0.5960 & 0.4160 & 0.3210 \\
\hline$a_{11}$ & $0.8759^{* * *}$ & 0.1487 & $0.8759^{* * *}$ & 0.1487 & $0.8854^{* * *}$ & 0.0829 \\
\hline$a_{12}$ & -0.1381 & 0.3532 & -0.1381 & 0.3532 & -0.1971 & 0.2362 \\
\hline$a_{13}$ & -0.0091 & 0.0132 & -0.0091 & 0.0132 & -0.0049 & 0.0069 \\
\hline$a_{14}$ & -0.0318 & 0.0487 & -0.0318 & 0.0487 & -0.0378 & 0.0433 \\
\hline$a_{15}$ & 0.0060 & 0.0070 & 0.0060 & 0.0070 & 0.0000 & --- \\
\hline$a_{16}$ & -0.0023 & 0.0155 & -0.0181 & 0.0475 & 0.0000 & --- \\
\hline$a_{17}$ & -0.0181 & 0.0475 & -0.0023 & 0.0155 & 0.0000 & --- \\
\hline$\sigma_{1}^{2}$ & $0.1895^{*}$ & 0.1076 & $0.1895^{*}$ & 0.1076 & $0.2041^{* * *}$ & 0.0665 \\
\hline$c_{2}$ & 0.2866 & 0.5180 & 0.2867 & 0.5180 & 0.2946 & 0.3189 \\
\hline$a_{21}$ & -0.0526 & 0.1622 & -0.0526 & 0.1622 & -0.0345 & 0.0941 \\
\hline$a_{22}$ & $0.6690^{* *}$ & 0.2800 & $0.6690^{* *}$ & 0.2800 & $0.6847^{* * *}$ & 0.2117 \\
\hline$a_{23}$ & 0.0002 & 0.0140 & 0.0002 & 0.0140 & 0.0018 & 0.0089 \\
\hline$a_{24}$ & -0.0270 & 0.0448 & -0.0271 & 0.0448 & -0.0265 & 0.0350 \\
\hline$a_{25}$ & 0.0005 & 0.0069 & 0.0005 & 0.0069 & 0.0000 & --- \\
\hline$a_{26}$ & 0.0020 & 0.0141 & 0.0101 & 0.0469 & 0.0000 & --- \\
\hline$a_{27}$ & 0.0101 & 0.0469 & 0.0020 & 0.0141 & 0.0000 & --- \\
\hline$\sigma_{2}^{2}$ & $0.0962^{* *}$ & 0.0459 & $0.0962^{* *}$ & 0.0459 & $0.1012^{* * *}$ & 0.0328 \\
\hline$C_{3}$ & 2.9578 & 11.8631 & 2.9520 & 11.8625 & 2.5051 & 6.9801 \\
\hline$a_{31}$ & 0.8302 & 3.9980 & 0.8309 & 3.9976 & 0.3975 & 2.2562 \\
\hline$a_{32}$ & -3.3261 & 8.6863 & -3.3217 & 8.6861 & -3.2420 & 6.9589 \\
\hline$a_{33}$ & 0.8521 & 0.2736 & $0.8521^{* * *}$ & 0.2735 & $0.7763^{* * *}$ & 0.1804 \\
\hline$a_{34}$ & -0.0521 & 1.4600 & -0.0512 & 1.4598 & -0.0673 & 0.9753 \\
\hline$a_{35}$ & -0.0679 & 0.1931 & -0.0679 & 0.1931 & 0.0000 & --- \\
\hline$a_{36}$ & 0.0123 & 0.4241 & -0.2138 & 1.7325 & 0.0000 & --- \\
\hline$a_{37}$ & -0.2138 & 1.7323 & 0.0122 & 0.4240 & 0.0000 & --- \\
\hline$\sigma_{3}^{2}$ & $108.7728^{* *}$ & 46.0860 & $108.7731^{* *}$ & 46.0887 & $113.0249^{* *}$ & 44.2724 \\
\hline
\end{tabular}

(Continued next page) 
Summary table for the estimation of the linear VAR models (Continued)

\begin{tabular}{|c|c|c|c|c|c|c|}
\hline \multirow[b]{2}{*}{ Parameter } & \multicolumn{2}{|c|}{ VAR(7)_1 } & \multicolumn{2}{|c|}{ VAR(7)_2 } & \multicolumn{2}{|c|}{ VAR(7)_R } \\
\hline & Estimate & S.E. & Estimate & S.E. & Estimate & S.E. \\
\hline$C_{4}$ & -0.5496 & 1.1537 & -0.5495 & 1.1537 & -0.5017 & 0.9027 \\
\hline$a_{41}$ & 0.2493 & 0.3529 & 0.2493 & 0.3528 & 0.1840 & 0.2624 \\
\hline$a_{42}$ & 0.0809 & 0.9224 & 0.0808 & 0.9224 & 0.1875 & 0.7994 \\
\hline$a_{43}$ & 0.0200 & 0.0387 & 0.0200 & 0.0387 & 0.0058 & 0.0209 \\
\hline$a_{44}$ & $0.9570^{* * *}$ & 0.0874 & $0.9570^{* * *}$ & 0.0874 & $0.9698^{* * *}$ & 0.0862 \\
\hline$a_{45}$ & -0.0159 & 0.0205 & -0.0159 & 0.0205 & 0.0000 & --- \\
\hline$a_{46}$ & 0.0014 & 0.0266 & 0.0196 & 0.1031 & 0.0000 & --- \\
\hline$a_{47}$ & 0.0196 & 0.1031 & 0.0014 & 0.0266 & 0.0000 & --- \\
\hline$\sigma_{4}^{2}$ & $1.5407^{* *}$ & 0.6573 & $1.5407^{* *}$ & 0.6573 & $1.6379^{* * *}$ & 0.4633 \\
\hline$C_{5}$ & 0.9498 & 19.9606 & 0.9369 & 19.9593 & 0.0040 & 16.9086 \\
\hline$a_{51}$ & 2.2047 & 6.8149 & 2.2060 & 6.8144 & 1.6303 & 5.4235 \\
\hline$a_{52}$ & -3.4148 & 21.7527 & -3.4039 & 21.7531 & -3.7464 & 17.2961 \\
\hline$a_{53}$ & 0.0866 & 0.4494 & 0.0865 & 0.4494 & 0.0086 & 0.4093 \\
\hline$a_{54}$ & -0.0130 & 2.4676 & -0.0105 & 2.4674 & -0.0748 & 1.9028 \\
\hline$a_{55}$ & 0.6490 & 0.3984 & 0.6491 & 0.3984 & $0.6990^{* * *}$ & 0.2140 \\
\hline$a_{56}$ & -0.2971 & 0.5761 & 0.2833 & 2.5875 & -0.2882 & 0.2164 \\
\hline$a_{57}$ & 0.2836 & 2.5871 & -0.2971 & 0.5761 & 0.7489 & 0.9752 \\
\hline$\sigma_{5}^{2}$ & $430.8574^{*}$ & 234.7470 & $430.8576^{*}$ & 234.7450 & $439.0567^{* *}$ & 193.2258 \\
\hline$C_{6}$ & 0.1816 & 7.4268 & 1.0397 & 2.9790 & -0.0549 & 6.8425 \\
\hline$a_{61}$ & 0.6001 & 1.9237 & 0.0704 & 0.9278 & 0.4937 & 1.6402 \\
\hline$a_{62}$ & -0.5828 & 7.1873 & -0.3794 & 2.9437 & -0.8464 & 7.2467 \\
\hline$a_{63}$ & -0.1018 & 0.2002 & -0.0045 & 0.0988 & -0.1053 & 0.1394 \\
\hline$a_{64}$ & -0.1862 & 0.7204 & 0.1287 & 0.4316 & -0.2140 & 0.5740 \\
\hline$a_{65}$ & $0.1850^{*}$ & 0.1006 & 0.0376 & 0.0522 & $0.1761^{* *}$ & 0.0727 \\
\hline$a_{66}$ & $0.7588^{* * *}$ & 0.1585 & $0.6874^{* * *}$ & 0.1767 & $0.7724^{* * *}$ & 0.1015 \\
\hline$a_{67}$ & -0.1288 & 0.6986 & 0.0026 & 0.0917 & 0.0185 & 0.5144 \\
\hline$\sigma_{6}^{2}$ & $54.9789^{* * *}$ & 24.6866 & $6.1525^{* *}$ & 2.7417 & $55.4785^{* * *}$ & 17.1303 \\
\hline
\end{tabular}

(Continued next page) 
Summary table for the estimation of the linear VAR models (Continued)

\begin{tabular}{|c|c|c|c|c|c|c|}
\hline \multirow[b]{2}{*}{ Parameter } & \multicolumn{2}{|c|}{ VAR(7)_1 } & \multicolumn{2}{|c|}{ VAR(7)_2 } & \multicolumn{2}{|c|}{ VAR(7)_R } \\
\hline & Estimate & S.E. & Estimate & S.E. & Estimate & S.E. \\
\hline$C_{7}$ & 1.0403 & 2.9787 & 0.1785 & 7.4258 & 0.9753 & 2.0104 \\
\hline$a_{71}$ & 0.0703 & 0.9279 & 0.6012 & 1.9235 & 0.0985 & 0.6721 \\
\hline$a_{72}$ & -0.3799 & 2.9435 & -0.5804 & 7.1872 & -0.4661 & 1.7547 \\
\hline$a_{73}$ & -0.0045 & 0.0988 & -0.1017 & 0.2002 & 0.0031 & 0.0513 \\
\hline$a_{74}$ & 0.1286 & 0.4316 & -0.1857 & 0.7205 & 0.1175 & 0.3163 \\
\hline$a_{75}$ & 0.0376 & 0.0522 & $0.1850^{*}$ & 0.1006 & 0.0279 & 0.0304 \\
\hline$a_{76}$ & 0.0026 & 0.0917 & -0.1288 & 0.6987 & 0.0038 & 0.0451 \\
\hline$a_{77}$ & $0.6874^{* * *}$ & 0.1767 & $0.7588^{* * *}$ & 0.1585 & $0.7163^{* * *}$ & 0.1234 \\
\hline$\sigma_{7}^{2}$ & $6.1525^{* *}$ & 2.7417 & $54.9767^{* *}$ & 24.6867 & $6.1875^{* * *}$ & 2.0599 \\
\hline$\rho_{12}$ & 0.1930 & 0.4958 & 0.1930 & 0.4957 & 0.1690 & 0.3181 \\
\hline$\rho_{13}$ & -0.1926 & 0.3981 & -0.1926 & 0.3981 & -0.2022 & 0.2078 \\
\hline$\rho_{14}$ & -0.0954 & 0.3438 & -0.0953 & 0.3438 & -0.1444 & 0.2452 \\
\hline$\rho_{15}$ & -0.0359 & 0.4359 & -0.0360 & 0.4358 & -0.0361 & 0.2568 \\
\hline$\rho_{16}$ & 0.0599 & 0.4651 & 0.1729 & 0.2806 & 0.0707 & 0.2584 \\
\hline$\rho_{17}$ & 0.1729 & 0.2806 & 0.0599 & 0.4651 & 0.1859 & 0.2017 \\
\hline$\rho_{23}$ & -0.2421 & 0.4198 & -0.2421 & 0.4198 & -0.2652 & 0.3853 \\
\hline$\rho_{24}$ & -0.0037 & 0.3415 & -0.0037 & 0.3415 & -0.0220 & 0.2404 \\
\hline$\rho_{25}$ & -0.2400 & 0.4468 & -0.2400 & 0.4468 & -0.2601 & 0.3613 \\
\hline$\rho_{26}$ & -0.2419 & 0.4010 & 0.0585 & 0.4755 & -0.2544 & 0.3003 \\
\hline$\rho_{27}$ & 0.0585 & 0.4755 & -0.2419 & 0.4010 & 0.0560 & 0.3563 \\
\hline$\rho_{34}$ & 0.0181 & 0.2362 & 0.0181 & 0.2362 & 0.0550 & 0.1556 \\
\hline$\rho_{35}$ & 0.6775 & 0.2213 & $0.6775^{* * *}$ & 0.2213 & $0.6833^{* * *}$ & 0.1487 \\
\hline$\rho_{36}$ & 0.2982 & 0.2701 & 0.1129 & 0.3363 & 0.3018 & 0.2231 \\
\hline$\rho_{37}$ & 0.1129 & 0.3363 & 0.2982 & 0.2701 & 0.1034 & 0.2222 \\
\hline$\rho_{45}$ & -0.0475 & 0.4372 & -0.0475 & 0.4372 & -0.0273 & 0.3139 \\
\hline$\rho_{46}$ & -0.1127 & 0.3051 & -0.2093 & 0.3292 & -0.1089 & 0.2198 \\
\hline$\rho_{47}$ & -0.2093 & 0.3292 & -0.1127 & 0.3051 & -0.2192 & 0.2632 \\
\hline$\rho_{56}$ & 0.4085 & 0.3197 & 0.3069 & 0.2971 & $0.4135^{* *}$ & 0.1974 \\
\hline$\rho_{57}$ & 0.3069 & 0.2971 & 0.4085 & 0.3197 & $0.3014^{*}$ & 0.1807 \\
\hline$\rho_{67}$ & 0.2401 & 0.3469 & 0.2400 & 0.3469 & 0.2412 & 0.2349 \\
\hline $\ln L$ & \multicolumn{2}{|c|}{-1629.5359} & \multicolumn{2}{|c|}{-1629.5359} & \multicolumn{2}{|c|}{-1640.0746} \\
\hline$A I C$ & \multicolumn{2}{|c|}{33.2725} & \multicolumn{2}{|c|}{33.2725} & \multicolumn{2}{|c|}{33.2442} \\
\hline
\end{tabular}

Notes: *, **, and $* * *$ represent the significance at $10 \%, 5 \%$, and $1 \%$, respectively 
Table A2 The Estimation Result for US System

\begin{tabular}{|c|c|c|c|c|c|c|}
\hline \multirow[b]{3}{*}{$\begin{array}{c}\text { Paramet } \\
\text { er }\end{array}$} & \multirow{2}{*}{\multicolumn{2}{|c|}{$\begin{array}{c}\text { VAR Model } \\
\text { Single Regime }\end{array}$}} & \multicolumn{4}{|c|}{ Markov Switching VAR Model } \\
\hline & & & \multicolumn{2}{|c|}{ Regime US1 } & \multicolumn{2}{|c|}{ Regime US2 } \\
\hline & Estimate & S.E. & Estimate & S.E. & Estimate & S.E. \\
\hline$C_{1}$ & $0.411^{* *}$ & 0.186 & 0.775 & 33.393 & 0.775 & 33.393 \\
\hline$\alpha_{1}(2)$ & & & & & -0.558 & 33.398 \\
\hline$a_{11}$ & $0.888 * * *$ & 0.053 & 0.944 & 14.219 & $0.920 * * * *$ & 0.058 \\
\hline$a_{12}$ & -0.195 & 0.147 & -0.340 & 11.169 & -0.200 & 0.172 \\
\hline$a_{13}$ & -0.005 & 0.003 & -0.006 & 0.405 & 0.003 & 0.004 \\
\hline$a_{14}$ & -0.039 & 0.025 & 0.007 & 4.944 & $-0.050 * *$ & 0.024 \\
\hline$\sigma_{1}^{2}$ & $0.194^{* * *}$ & 0.038 & 0.133 & 13.593 & 0.133 & 13.593 \\
\hline$\lambda_{1}$ & & & 1.000 & --- & 1.027 & 52.387 \\
\hline$C_{2}$ & $0.289 *$ & 0.161 & 0.813 & 88.985 & 0.813 & 88.985 \\
\hline$\alpha_{2}(2)$ & & & & & -0.707 & 89.013 \\
\hline$a_{21}$ & -0.031 & 0.050 & -0.035 & 31.824 & -0.008 & 0.025 \\
\hline$a_{22}$ & $0.688 * * *$ & 0.110 & 0.429 & 26.747 & $0.776^{* * *}$ & 0.085 \\
\hline$a_{23}$ & 0.002 & 0.005 & 0.014 & 0.845 & 0.000 & 0.002 \\
\hline$a_{24}$ & -0.0028 & 0.022 & -0.106 & 9.235 & 0.006 & 0.012 \\
\hline$\sigma_{2}^{2}$ & $0.098 * * *$ & 0.021 & 0.192 & 18.371 & 0.192 & 18.371 \\
\hline$\lambda_{2}$ & & & 1.000 & --- & 0.340 & 16.267 \\
\hline$C_{3}$ & 2.668 & 4.478 & -7.228 & 990.488 & -7.228 & 990.488 \\
\hline$\alpha_{3}(2)$ & & & & & 11.492 & 990.708 \\
\hline$a_{31}$ & 0.321 & 1.276 & 6.488 & 667.935 & -0.851 & 1.625 \\
\hline$a_{32}$ & -3.333 & 3.716 & -10.242 & 1508.937 & 1.795 & 3.984 \\
\hline$a_{33}$ & $0.775^{* * *}$ & 0.093 & 0.611 & 17.381 & $0.728 * * *$ & 0.076 \\
\hline$a_{34}$ & -0.045 & 0.569 & 0.567 & 134.015 & -0.555 & 0.513 \\
\hline$\sigma_{3}^{2}$ & $110.967 * * *$ & 27.006 & 136.250 & 11987 & 136.250 & 11987 \\
\hline$\lambda_{3}$ & & & 1.000 & --- & 0.705 & 30.994 \\
\hline
\end{tabular}

(continued next page) 
Table A2 The Estimation Result for US System (Continued)

\begin{tabular}{|c|c|c|c|c|c|c|}
\hline \multirow[b]{3}{*}{ Parameter } & \multirow{2}{*}{\multicolumn{2}{|c|}{$\begin{array}{c}\text { VAR Model } \\
\text { Single Regime }\end{array}$}} & \multicolumn{4}{|c|}{ Markov Switching VAR Model } \\
\hline & & & \multicolumn{2}{|c|}{ Regime US1 } & \multicolumn{2}{|c|}{ Regime US2 } \\
\hline & Estimate & S.E. & Estimate & S.E. & Estimate & S.E. \\
\hline$C_{4}$ & -0.509 & 0.669 & -1.653 & 277.129 & -1.653 & 277.129 \\
\hline$\alpha_{4}(2)$ & & & & & 1.163 & 277.130 \\
\hline$a_{41}$ & 0.188 & 0.172 & -0.238 & 98.429 & $0.281^{* *}$ & 0.137 \\
\hline$a_{42}$ & 0.191 & 0.644 & 1.046 & 126.141 & 0.180 & 0.599 \\
\hline$a_{43}$ & 0.006 & 0.016 & -0.042 & 3.880 & 0.019 & 0.015 \\
\hline$a_{44}$ & $0.968 * * *$ & 0.062 & 1.130 & 29.935 & $0.914 * * *$ & 0.044 \\
\hline$\sigma_{4}^{2}$ & $1.664^{* * *}$ & 0.292 & 2.375 & 21.795 & 2.375 & 21.795 \\
\hline$\lambda_{4}$ & & & 1.000 & --- & 0.621 & 27.831 \\
\hline$\rho_{12}$ & 0.134 & 0.185 & 0.632 & 54.435 & -0.237 & 0.188 \\
\hline$\rho_{13}$ & -0.184 & 0.130 & 0.063 & 68.210 & $-0.299 *$ & 0.158 \\
\hline$\rho_{14}$ & -0.133 & 0.150 & 0.166 & 86.350 & -0.191 & 0.163 \\
\hline$\rho_{23}$ & -0.255 & 0.213 & -0.329 & 39.574 & 0.036 & 0.201 \\
\hline$\rho_{24}$ & 0.012 & 0.153 & 0.722 & 33.300 & -0.013 & 0.193 \\
\hline$\rho_{34}$ & 0.036 & 0.110 & -0.401 & 56.026 & 0.232 & 0.241 \\
\hline$P_{u 1 u 1}$ & & & \multicolumn{4}{|c|}{$0.747 * * *(0.193)$} \\
\hline$P_{u 2 u 2}$ & & & \multicolumn{4}{|c|}{$0.925^{* * * *}(0.076)$} \\
\hline $\ln L$ & \multicolumn{2}{|c|}{-648.821} & \multicolumn{3}{|c|}{-551.757} & \\
\hline AIC & \multicolumn{2}{|c|}{13.054} & \multicolumn{3}{|c|}{11.803} & \\
\hline
\end{tabular}

Note: Values in parenthesis refer to standard deviations. *, **, and *** represent the significance at $10 \%, 5 \%$, and $1 \%$, respectively. 
Table A3 The Estimation Results for Model A (Stock Return, Housing Return, GDP Growth)

\begin{tabular}{|c|c|c|c|c|c|c|}
\hline \multirow{3}{*}{ Parameter } & \multirow{2}{*}{\multicolumn{2}{|c|}{$\begin{array}{l}\text { VAR Model } \\
\text { Single Regime }\end{array}$}} & \multicolumn{4}{|c|}{ Markov Switching VAR Model } \\
\hline & & & \multicolumn{2}{|c|}{ Regime HK1 } & \multicolumn{2}{|c|}{ Regime HK2 } \\
\hline & Estimate & S.E. & Estimate & S.E. & Estimate & S.E. \\
\hline$C_{1}$ & 2.885 & 3.290 & -6.963 & 26.123 & $8.975 * *$ & 4.408 \\
\hline$a_{11}$ & $0.703^{* * *}$ & 0.086 & 0.807 & 1.584 & $0.727^{* * *}$ & 0.100 \\
\hline$a_{12}$ & -0.259 & 0.164 & 0.071 & 3.519 & -0.107 & 0.200 \\
\hline$a_{13}$ & 0.148 & 0.611 & 1.976 & 1.279 & -1.460 & 1.013 \\
\hline$\sigma_{1}^{2}$ & $439.878 * * *$ & 63.459 & 249.835 & 302.865 & 249.835 & 302.865 \\
\hline$\lambda_{1}$ & & & 1.000 & --- & 1.270 & 0.781 \\
\hline$c_{2}$ & 0.381 & 1.148 & -10.487 & 6.747 & $3.344 * *$ & 1.435 \\
\hline$a_{21}$ & $0.145^{* * *}$ & 0.030 & 0.401 & 0.640 & $0.136 * * *$ & 0.027 \\
\hline$a_{22}$ & $0.782 * * *$ & 0.067 & 0.497 & 1.551 & $0.845 * * *$ & 0.065 \\
\hline$a_{23}$ & -0.126 & 0.252 & 0.382 & 0.438 & $-0.615 * *$ & 0.292 \\
\hline$\sigma_{2}^{2}$ & $58.955 * * *$ & 8.314 & 27.680 & 76.664 & 27.680 & 76.664 \\
\hline$\lambda_{2}$ & & & 1.000 & --- & 1.266 & 1.768 \\
\hline$C_{3}$ & $1.024 * *$ & 0.440 & 0.598 & 13.008 & $1.329 * * *$ & 0.393 \\
\hline$a_{31}$ & $0.040^{* * *}$ & 0.012 & -0.002 & 0.308 & $0.045^{* * *}$ & 0.009 \\
\hline$a_{32}$ & -0.004 & 0.026 & 0.142 & 0.480 & -0.013 & 0.019 \\
\hline$a_{33}$ & $0.704 * * *$ & 0.070 & 0.822 & 0.565 & $0.643 * * *$ & 0.075 \\
\hline$\sigma_{3}^{2}$ & $6.404^{* * *}$ & 0.922 & 20.480 & 43.547 & 20.480 & 43.547 \\
\hline$\lambda_{3}$ & & & 1.000 & --- & 0.379 & 0.404 \\
\hline$\rho_{12}$ & $0.395 * * *$ & 0.090 & 0.744 & 0.906 & 0.302 & 0.112 \\
\hline$\rho_{13}$ & $0.313^{* * *}$ & 0.108 & -0.154 & 0.770 & $0.508^{* * *}$ & 0.095 \\
\hline$\rho_{23}$ & $0.218^{* *}$ & 0.104 & 0.072 & 0.811 & $0.393 * * *$ & 0.116 \\
\hline$\alpha_{0}$ & & & & $2.265 * *$ & (1.098) & \\
\hline$\alpha_{1}$ & & & & $3.701 *$ & (1.931) & \\
\hline$P_{h 1 h 1}$ & & & & 0.906 & & \\
\hline$P_{h 2 h 2}$ & & & & 0.976 & & \\
\hline $\ln L$ & -1042. & & & 90.506 & & \\
\hline AIC & 20. & & & 19.971 & & \\
\hline
\end{tabular}

Note: Values in parenthesis are standard deviations. ${ }^{*},{ }^{* *}$, and ${ }^{* * *}$ represent the significance at $10 \%, 5 \%$, and $1 \%$, respectively. 
Table A4 The Estimation Results for Model B

(VAR model with Term Spread as exogenous variable )

\begin{tabular}{|c|c|c|c|c|c|c|}
\hline \multirow{3}{*}{ Parameter } & \multirow{2}{*}{\multicolumn{2}{|c|}{$\begin{array}{l}\text { VAR Model } \\
\text { Single Regime }\end{array}$}} & \multicolumn{4}{|c|}{ Markov Switching VAR Model } \\
\hline & & & \multicolumn{2}{|c|}{ Regime HK1 } & \multicolumn{2}{|c|}{ Regime HK2 } \\
\hline & Estimate & S.E. & Estimate & S.E. & Estimate & S.E. \\
\hline$C_{1}$ & -0.139 & 4.991 & -32.811 & 7961.761 & 8.377 & 6.656 \\
\hline$a_{11}$ & $0.700^{* * *}$ & 0.092 & 0.334 & 349.347 & $0.742^{* * *}$ & 0.116 \\
\hline$a_{12}$ & $-0.292 *$ & 0.178 & 0.566 & 348.388 & -0.126 & 0.212 \\
\hline$a_{13}$ & 0.188 & 0.642 & 1.838 & 221.827 & -1.391 & 0.911 \\
\hline$\gamma_{z 1}$ & 1.735 & 2.368 & 16.190 & 4484.226 & 0.284 & 2.683 \\
\hline$\gamma_{u 1}$ & 1.400 & 7.298 & 9.838 & 9085.480 & -2.335 & 8.281 \\
\hline$\sigma_{1}^{2}$ & $435.797 * * *$ & 62.064 & 173.595 & 33023.187 & 173.595 & 33023.187 \\
\hline$\lambda_{1}$ & & & 1.000 & --- & 1.524 & 144.982 \\
\hline$c_{2}$ & -1.456 & 2.134 & -12.806 & 1118.885 & 2.205 & 2.478 \\
\hline$a_{21}$ & $0.139 * * *$ & 0.032 & 0.382 & 116.212 & $0.129 * * *$ & 0.029 \\
\hline$a_{22}$ & $0.766^{* * *}$ & 0.076 & 0.520 & 93.742 & $0.824 * * *$ & 0.071 \\
\hline$a_{23}$ & -0.091 & 0.274 & 0.436 & 75.211 & $-0.518^{*}$ & 0.307 \\
\hline$\gamma_{z 2}$ & 1.042 & 0.917 & 1.381 & 1112.747 & 0.493 & 0.846 \\
\hline$\gamma_{u 2}$ & 2.504 & 3.001 & -2.289 & 3362.321 & 2.118 & 2.900 \\
\hline$\sigma_{2}^{2}$ & $56.722 * * *$ & 9.311 & 25.630 & 5932.499 & 25.630 & 5932.499 \\
\hline$\lambda_{2}$ & & & 1.000 & --- & 1.304 & 150.915 \\
\hline$C_{3}$ & 0.816 & 0.912 & -1.652 & 4130.722 & 0.873 & 0.657 \\
\hline$a_{31}$ & $0.037 * * *$ & 0.013 & -0.072 & 95.620 & $0.045^{* * *}$ & 0.009 \\
\hline$a_{32}$ & -0.005 & 0.034 & 0.244 & 99.762 & -0.021 & 0.020 \\
\hline$a_{33}$ & 0.711 & 0.076 & 0.743 & 159.065 & $0.667 * * *$ & 0.074 \\
\hline$\gamma_{z 3}$ & 0.115 & 0.355 & 1.566 & 1649.230 & 0.234 & 0.235 \\
\hline$\gamma_{u 3}$ & 0.746 & 1.004 & 5.216 & 1769.083 & 0.230 & 0.698 \\
\hline$\sigma_{3}^{2}$ & $6.313^{* * *}$ & 1.133 & 18.828 & 3152.976 & 18.828 & 3152.976 \\
\hline$\lambda_{3}$ & & & 1.000 & --- & 0.389 & 32.612 \\
\hline$\rho_{12}$ & $0.387 * * *$ & 0.103 & 0.830 & 27.776 & $0.307 * *$ & 0.137 \\
\hline$\rho_{13}$ & $0.309 * * *$ & 0.112 & -0.348 & 301.640 & $0.519 * * *$ & 0.103 \\
\hline$\rho_{23}$ & $0.203^{*}$ & 0.118 & 0.124 & 346.273 & $0.381^{* * *}$ & 0.143 \\
\hline$\alpha_{0}$ & & & & $2.397 * *$ & $(1.040)$ & \\
\hline$\alpha_{1}$ & & & & $3.856^{*}$ & (2.269) & \\
\hline$P_{h 1 h 1}$ & & & & 0.917 & & \\
\hline$P_{h 2 h 2}$ & & & & 0.979 & & \\
\hline $\ln L$ & -1040 & & & -973.731 & & \\
\hline AIC & & & & 19.878 & & \\
\hline
\end{tabular}


Table A5 The Estimation Results for Model C (VAR model with TED Spread as exogenous variable )

\begin{tabular}{|c|c|c|c|c|c|c|}
\hline \multirow[b]{3}{*}{ Parameter } & \multirow{2}{*}{\multicolumn{2}{|c|}{$\begin{array}{l}\text { VAR Model } \\
\text { Single Regime }\end{array}$}} & \multicolumn{4}{|c|}{ Markov Switching VAR Model } \\
\hline & & & \multicolumn{2}{|c|}{ Regime HK1 } & \multicolumn{2}{|c|}{ Regime HK2 } \\
\hline & Estimate & S.E. & Estimate & S.E. & Estimate & S.E. \\
\hline$c_{1}$ & 5.397 & 4.520 & -10.640 & 60.308 & $16.454^{* * *}$ & 5.831 \\
\hline$a_{11}$ & $0.656^{* * *}$ & 0.095 & 0.764 & 1.590 & $0.569 * * *$ & 0.121 \\
\hline$a_{12}$ & -0.223 & 0.162 & 0.119 & 4.485 & -0.050 & 0.210 \\
\hline$a_{13}$ & 0.322 & 0.668 & 1.804 & 3.431 & -1.294 & 1.099 \\
\hline$\gamma_{z 1}$ & -4.679 & 7.077 & 7.311 & 68.204 & -11.911 & 7.753 \\
\hline$\gamma_{u 1}$ & $-16.886 * *$ & 8.026 & -11.222 & 107.627 & $-18.088 *$ & 10.025 \\
\hline$\sigma_{1}^{2}$ & $418.605^{* * *}$ & 62.973 & 202.478 & 639.763 & 202.478 & 639.763 \\
\hline$\lambda_{1}$ & & & 1.000 & --- & 1.330 & 2.102 \\
\hline$C_{2}$ & 0.155 & 2.131 & -6.230 & 8.485 & $3.796 *$ & 2.221 \\
\hline$a_{21}$ & $0.139 * * *$ & 0.033 & 0.386 & 0.665 & $0.108^{* * *}$ & 0.039 \\
\hline$a_{22}$ & $0.792 * * *$ & 0.068 & 0.437 & 1.384 & $0.845^{* * *}$ & 0.069 \\
\hline$a_{23}$ & -0.084 & 0.268 & 0.408 & 0.541 & -0.488 & 0.350 \\
\hline$\gamma_{z 2}$ & 0.093 & 3.127 & -3.946 & 11.824 & -1.121 & 2.524 \\
\hline$\gamma_{u 2}$ & $-6.795^{*}$ & 3.783 & -7.418 & 61.065 & $-6.526^{*}$ & 3.482 \\
\hline$\sigma_{2}^{2}$ & $56.200 * * *$ & 9.063 & 28.473 & 66.822 & 28.473 & 66.822 \\
\hline$\lambda_{2}$ & & & 1.000 & --- & 1.237 & 1.488 \\
\hline$C_{3}$ & $1.437 * *$ & 0.682 & 0.665 & 18.240 & $1.858^{* * *}$ & 0.482 \\
\hline$a_{31}$ & $0.035^{* *}$ & 0.017 & -0.008 & 0.434 & $0.032 * * *$ & 0.012 \\
\hline$a_{32}$ & -0.002 & 0.027 & 0.143 & 0.688 & -0.011 & 0.019 \\
\hline$a_{33}$ & $0.718^{* * *}$ & 0.070 & 0.810 & 1.153 & $0.671^{* * *}$ & 0.071 \\
\hline$\gamma_{\mathrm{z} 3}$ & -0.687 & 0.626 & 0.214 & 36.483 & $-0.954 * *$ & 0.427 \\
\hline$\gamma_{u 3}$ & -0.670 & 1.645 & 3.119 & 61.906 & -1.083 & 1.188 \\
\hline$\sigma_{3}^{2}$ & $6.275^{* * *}$ & 0.908 & 16.137 & 39.107 & 16.137 & 39.107 \\
\hline$\lambda_{3}$ & & & 1.000 & --- & 0.397 & 0.481 \\
\hline$\rho_{12}$ & $0.371^{* * *}$ & 0.104 & 0.709 & 0.443 & 0.252 & 0.153 \\
\hline$\rho_{13}$ & $0.298 * * *$ & 0.114 & -0.166 & 1.191 & $0.493^{* * *}$ & 0.100 \\
\hline$\rho_{23}$ & 0.213 & 0.140 & 0.128 & 1.225 & $0.407 * * *$ & 0.146 \\
\hline$\alpha_{0}$ & & & & $1.847^{* *}$ & $(0.889)$ & \\
\hline$\alpha_{1}$ & & & & $3.116^{* *}$ & (1.411) & \\
\hline$P_{h 1 h 1}$ & & & & 0.864 & & \\
\hline$P_{h 2 h 2}$ & & & & 0.958 & & \\
\hline $\ln L$ & -1038. & 295 & & 2.759 & & \\
\hline AIC & & 627 & & 20.054 & & \\
\hline
\end{tabular}


Table A6 The Estimation Results for Model D

(VAR model with stock return as exogenous variable )

\begin{tabular}{|c|c|c|c|c|c|c|}
\hline \multirow[b]{3}{*}{ Par } & \multirow{2}{*}{\multicolumn{2}{|c|}{$\begin{array}{l}\text { VAR Model } \\
\text { Single Regime }\end{array}$}} & \multicolumn{4}{|c|}{ Markov Switching VAR Model } \\
\hline & & & \multicolumn{2}{|c|}{ Regime HK1 } & \multicolumn{2}{|c|}{ Regime HK2 } \\
\hline & Estimate & S.E. & Estimate & S.E. & Estimate & S.E. \\
\hline$c_{1}$ & 1.845 & 2.780 & -1.874 & 531.299 & $7.298 * *$ & 3.410 \\
\hline$a_{11}$ & $0.725 * * *$ & 0.102 & 0.789 & 19.359 & $0.689 * * *$ & 0.136 \\
\hline$a_{12}$ & $-0.310^{* *}$ & 0.123 & -0.223 & 25.194 & -0.125 & 0.146 \\
\hline$a_{13}$ & 0.372 & 0.515 & 1.666 & 23.179 & -0.980 & 0.812 \\
\hline$\gamma_{z 1}$ & 0.006 & 0.136 & -0.317 & 13.367 & 0.179 & 0.175 \\
\hline$\gamma_{u 1}$ & $1.496 * * *$ & 0.215 & 1.156 & 28.335 & $1.434^{* * *}$ & 0.313 \\
\hline$\sigma_{1}^{2}$ & $255.095^{* * *}$ & 30.550 & 165.908 & 2936.829 & 165.908 & 2936.829 \\
\hline$\lambda_{1}$ & & & 1.000 & --- & 1.162 & 10.290 \\
\hline$c_{2}$ & 0.635 & 1.390 & -11.080 & 140.606 & $3.102 *$ & 1.671 \\
\hline$a_{21}$ & $0.200^{* * *}$ & 0.037 & 0.415 & 5.782 & $0.143^{* * *}$ & 0.042 \\
\hline$a_{22}$ & $0.774^{* * *}$ & 0.060 & 0.384 & 7.095 & $0.840^{* * *}$ & 0.064 \\
\hline$a_{23}$ & -0.163 & 0.266 & 0.391 & 11.526 & $-0.565^{*}$ & 0.328 \\
\hline$\gamma_{z 2}$ & $-0.128 * *$ & 0.065 & 0.022 & 6.834 & -0.006 & 0.072 \\
\hline$\gamma_{u 2}$ & $0.196 * *$ & 0.080 & 0.299 & 16.032 & $0.174 *$ & 0.097 \\
\hline$\sigma_{2}^{2}$ & $52.714^{* * *}$ & 9.219 & 23.500 & 835.186 & 23.500 & 835.186 \\
\hline$\lambda_{2}$ & & & 1.000 & --- & 1.338 & 23.813 \\
\hline$c_{3}$ & $1.005 * *$ & 0.477 & 3.345 & 235.458 & $1.274^{* * *}$ & 0.448 \\
\hline$a_{31}$ & $0.040 *$ & 0.020 & -0.031 & 4.214 & $0.045^{* * *}$ & 0.013 \\
\hline$a_{32}$ & -0.005 & 0.032 & 0.361 & 7.440 & -0.014 & 0.022 \\
\hline$a_{33}$ & $0.708 * * *$ & 0.073 & 0.759 & 16.043 & $0.659 * * *$ & 0.076 \\
\hline$\gamma_{z 3}$ & 0.000 & 0.031 & -0.129 & 8.639 & 0.003 & 0.021 \\
\hline$\gamma_{u 3}$ & 0.025 & 0.040 & -0.372 & 17.544 & $0.042 *$ & 0.025 \\
\hline$\sigma_{3}^{2}$ & $6.351^{* * *}$ & 1.220 & 14.938 & 514.751 & 14.938 & 514.751 \\
\hline$\lambda_{3}$ & & & 1.000 & --- & 0.432 & 7.445 \\
\hline$\rho_{12}$ & $0.350 * *$ & 0.145 & 0.736 & 6.334 & 0.205 & 0.180 \\
\hline$\rho_{13}$ & $0.335 * *$ & 0.131 & 0.060 & 24.372 & $0.500 * * *$ & 0.101 \\
\hline$\rho_{23}$ & $0.211^{* *}$ & 0.107 & 0.340 & 24.737 & $0.357 * *$ & 0.148 \\
\hline$\alpha_{0}$ & & & & $2.358 * *$ & (1.031) & \\
\hline$\alpha_{1}$ & & & & $3.821^{*}$ & $(2.242)$ & \\
\hline$P_{h 1 h 1}$ & & & & 0.914 & & \\
\hline$P_{h 2 h 2}$ & & & & 0.979 & & \\
\hline $\ln L$ & -1009. & & & 954.951 & & \\
\hline AIC & 20. & & & 19.514 & & \\
\hline
\end{tabular}


Table A7 The Estimation Results for Model E (VAR model with housing return as exogenous variable )

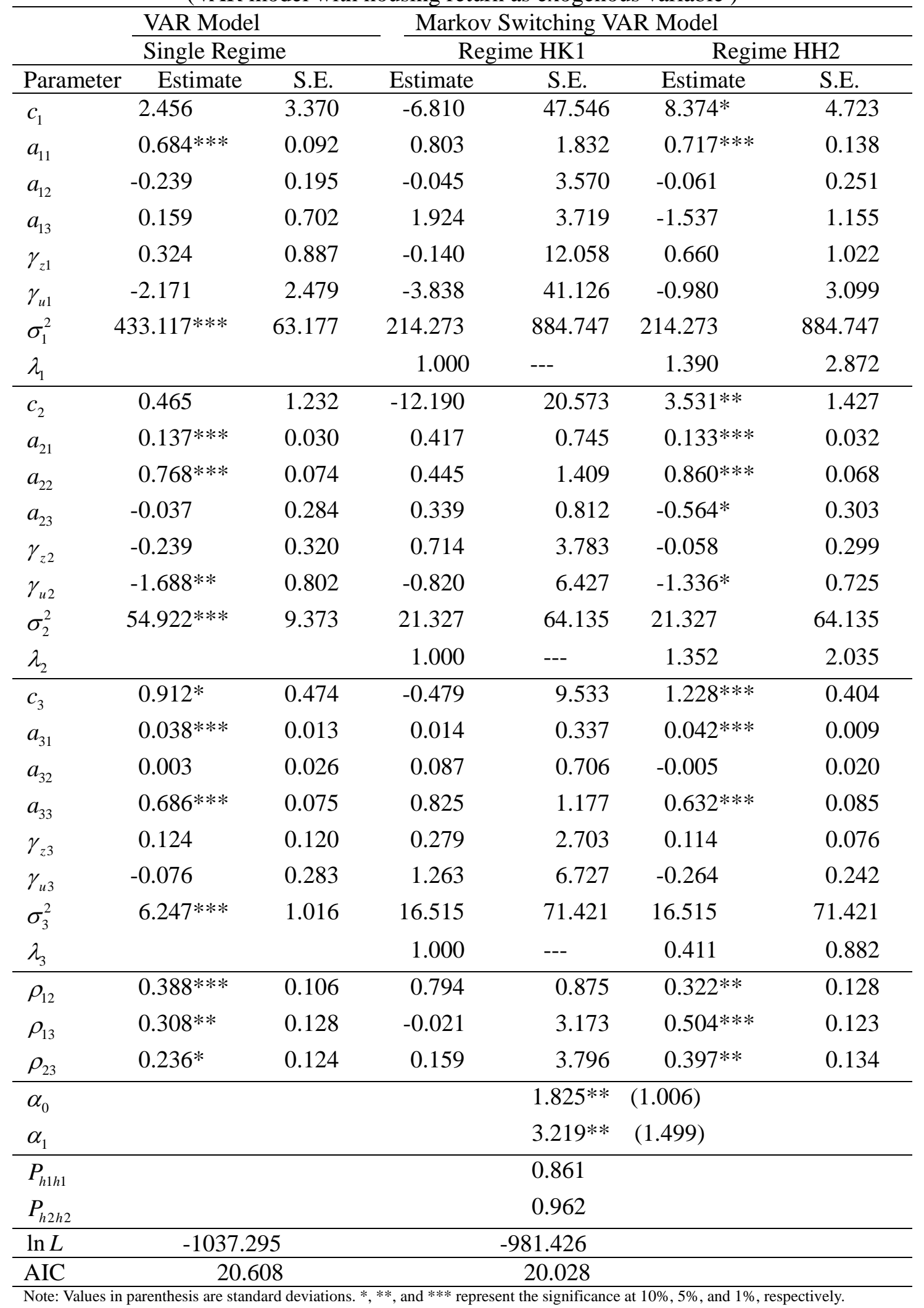



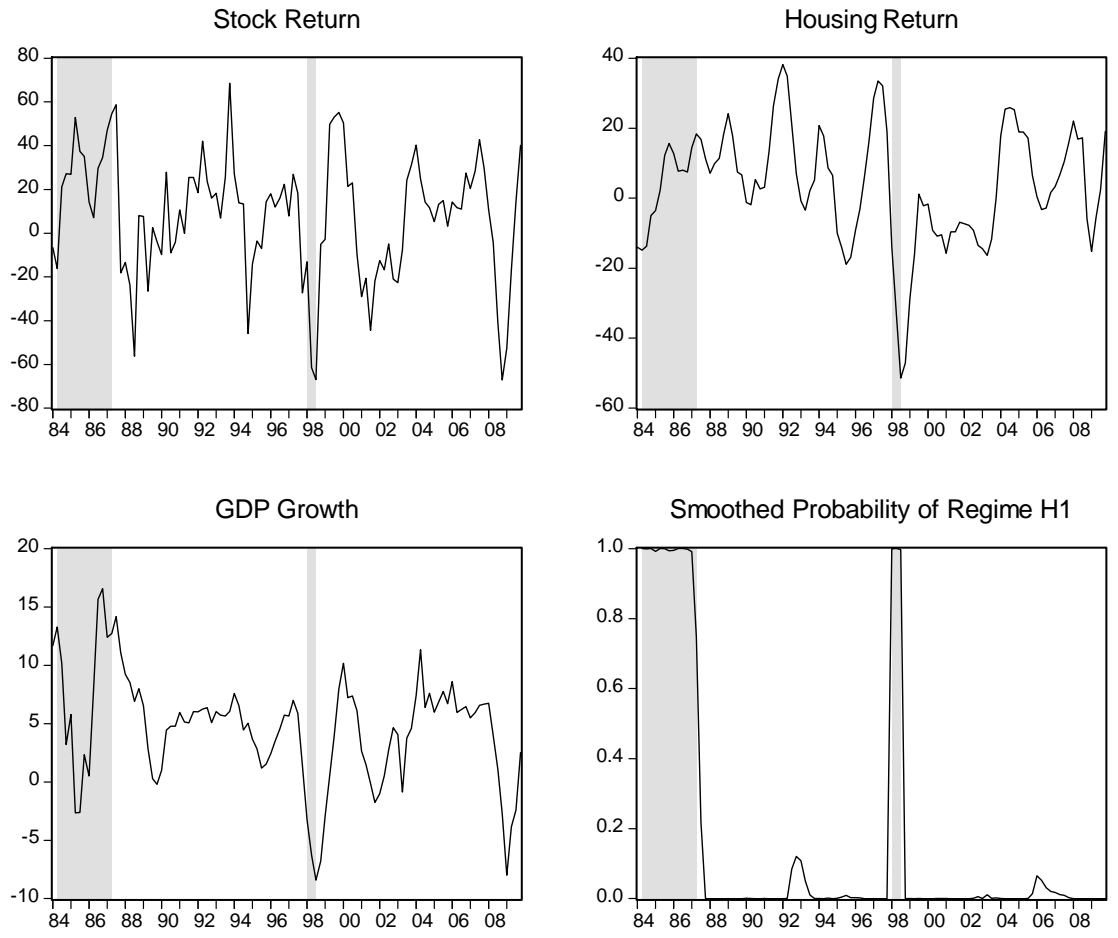

Figure A-1 The data for Hong Kong and the smoothed probabilities of regime H1 for Model A (Shaded areas indicate the periods of regime H1)
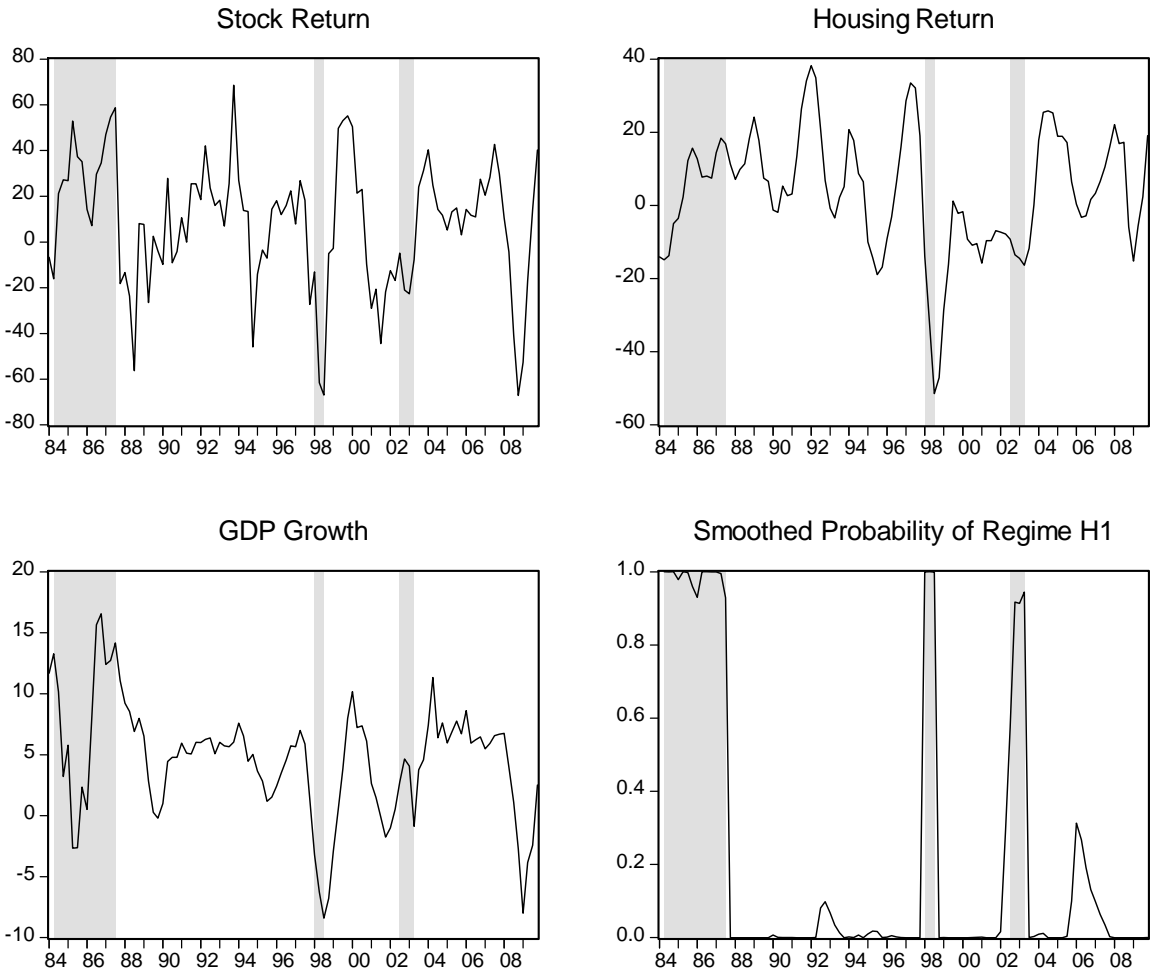

Figure A-2 The data of Hong Kong and smoothed probabilities of regime H1 for Model C (Shaded areas indicate the periods of regime H1) 

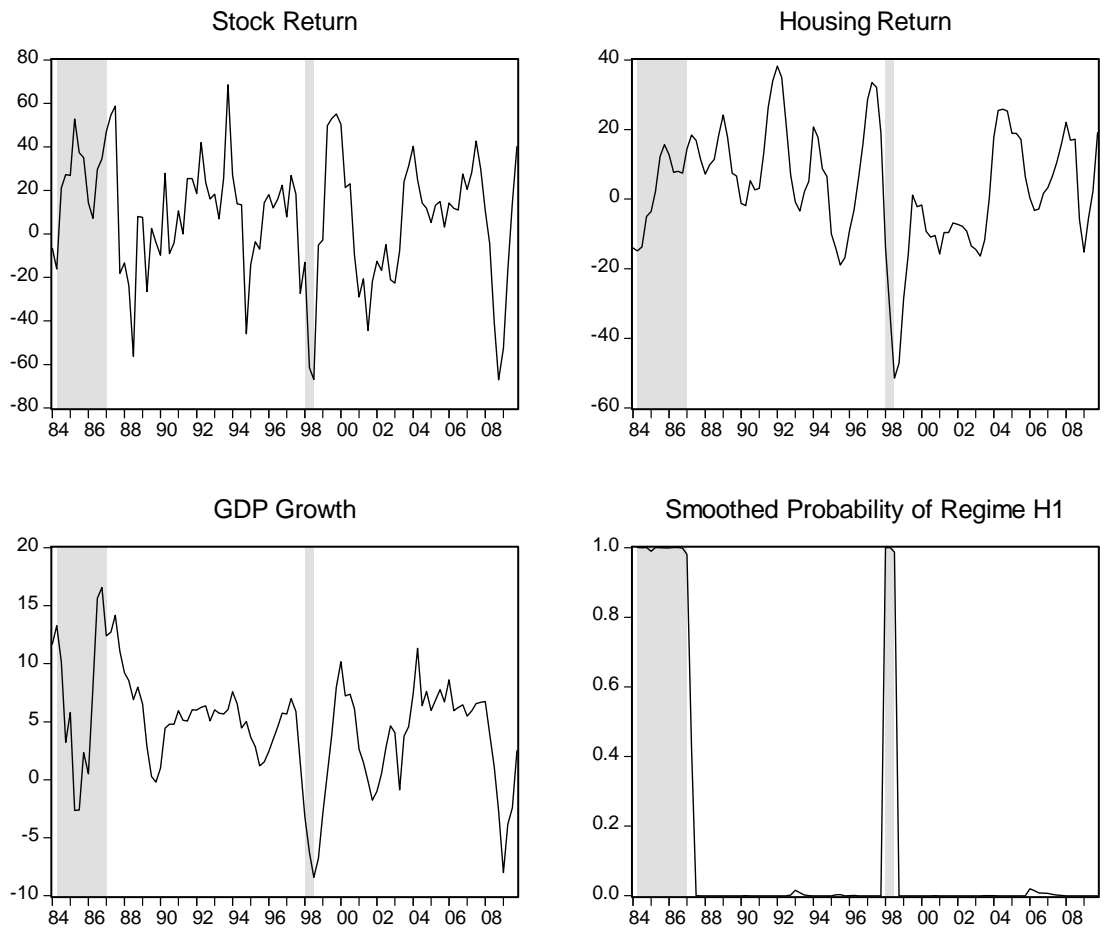

Figure A-3 The data of Hong Kong and smoothed probabilities of regime H1 for Model D (Shaded areas indicate the periods of regime H1)
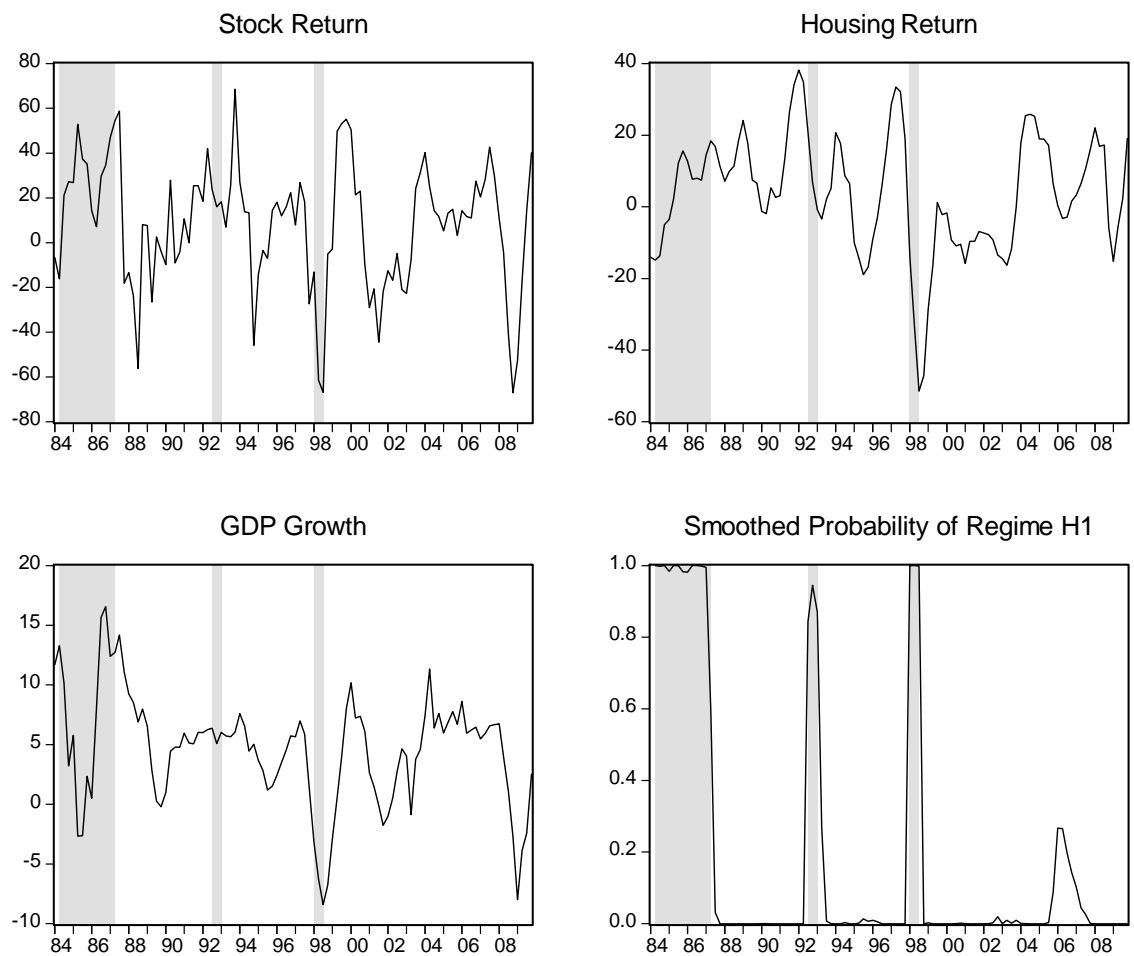

Figure A-4 The data of Hong Kong and smoothed probabilities of regime $\mathrm{H} 1$ for Model E (Shaded areas indicate the periods of regime H1) 
Appendix B: More Details of the Data

Table B-1 Summary Statistics for US data (1984Q1-2009Q4)

\begin{tabular}{|lcccc|}
\hline & Term Spread & TED Spread & Stock Return & Housing Return \\
\hline Mean & 1.741 & 0.650 & 3.887 & 1.380 \\
Median & 1.724 & 0.513 & 6.616 & 1.493 \\
Maximum & 3.611 & 3.333 & 36.146 & 8.810 \\
Minimum & -0.628 & 0.097 & -50.240 & -8.972 \\
Std. Dev. & 1.173 & 0.497 & 17.519 & 3.373 \\
Skewness & -0.162 & 2.051 & -0.899 & -0.472 \\
Kurtosis & 1.779 & 10.079 & 3.535 & 3.410 \\
Observations & 104 & 104 & 104 & 104 \\
\hline
\end{tabular}

Table B-2 Correlation Coefficients for US data

\begin{tabular}{|l|c|c|c|c|}
\hline & Term Spread & TED Spread & Stock Return & Housing Return \\
\hline Term Spread & 1.000 & & & \\
\hline TED Spread & -0.058 & 1.000 & & \\
\hline Stock Return & -0.262 & -0.166 & 1.000 & \\
\hline Housing Return & -0.166 & -0.423 & 0.228 & 1.000 \\
\hline
\end{tabular}

Table B-3 Summary Statistics for HK data (1984Q1-2009Q4)

\begin{tabular}{|lccc|}
\hline & $\begin{array}{c}\text { Stock } \\
\text { Return }\end{array}$ & $\begin{array}{c}\text { Housing } \\
\text { Return }\end{array}$ & $\begin{array}{c}\text { GDP } \\
\text { Growth }\end{array}$ \\
\hline Mean & 7.908 & 3.603 & 4.553 \\
Median & 12.579 & 4.203 & 5.575 \\
Maximum & 68.573 & 38.193 & 16.561 \\
Minimum & -67.128 & -51.432 & -8.406 \\
Std. Dev. & 28.126 & 16.471 & 4.691 \\
Skewness & -0.517 & -0.469 & -0.330 \\
Kurtosis & 3.228 & 3.727 & 3.662 \\
Observations & 104 & 104 & 104 \\
\hline
\end{tabular}

Table B-4 Correlation Coefficients for HK data

\begin{tabular}{|l|c|c|c|}
\hline & Stock Return & Housing Return & GDP Growth Rate \\
\hline Stock Return & 1.000 & & \\
\hline Housing Return & 0.395 & 1.000 & \\
\hline GDP Growth Rate & 0.471 & 0.491 & 1.000 \\
\hline
\end{tabular}



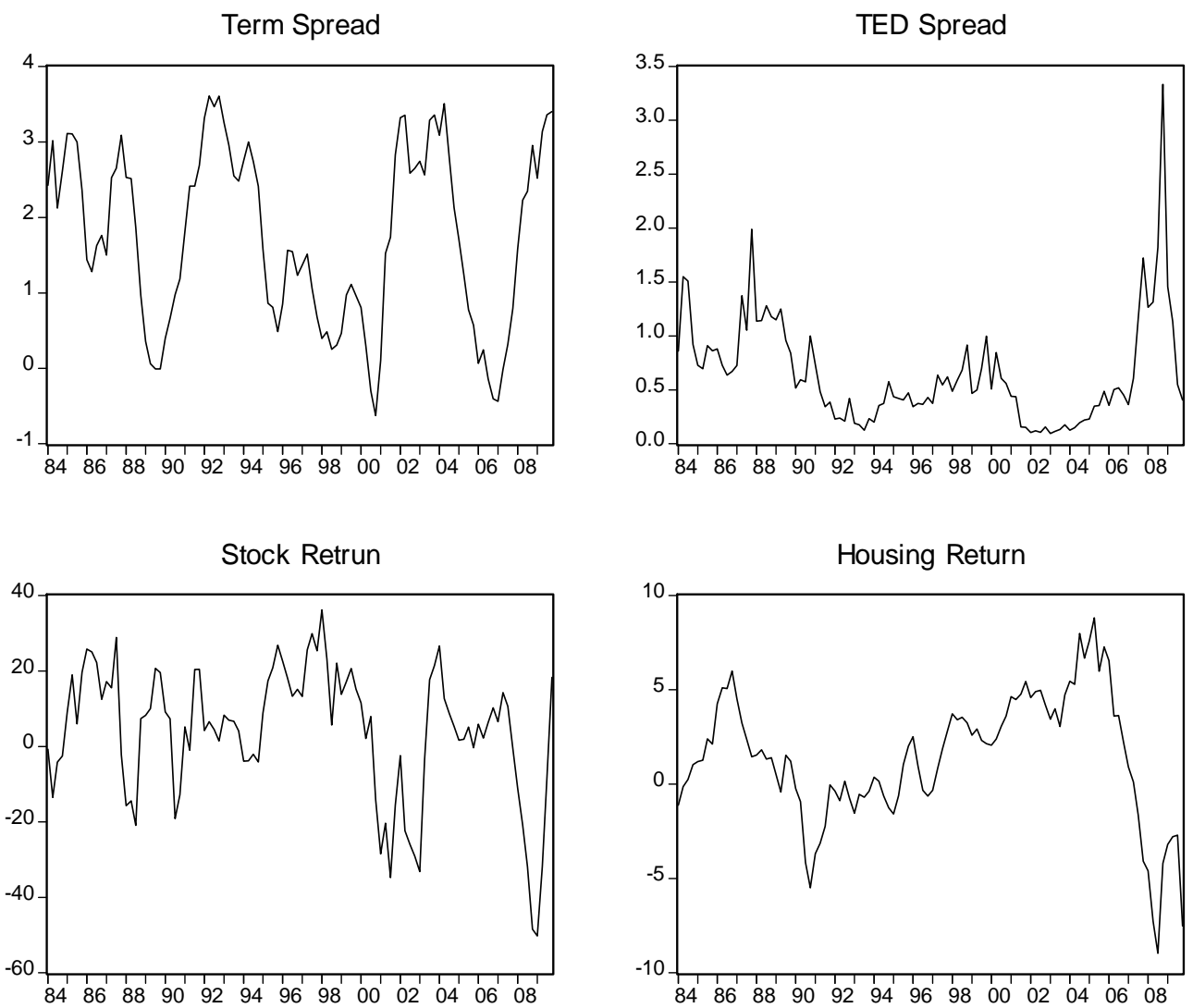

Figure B-1 The time plots for US data
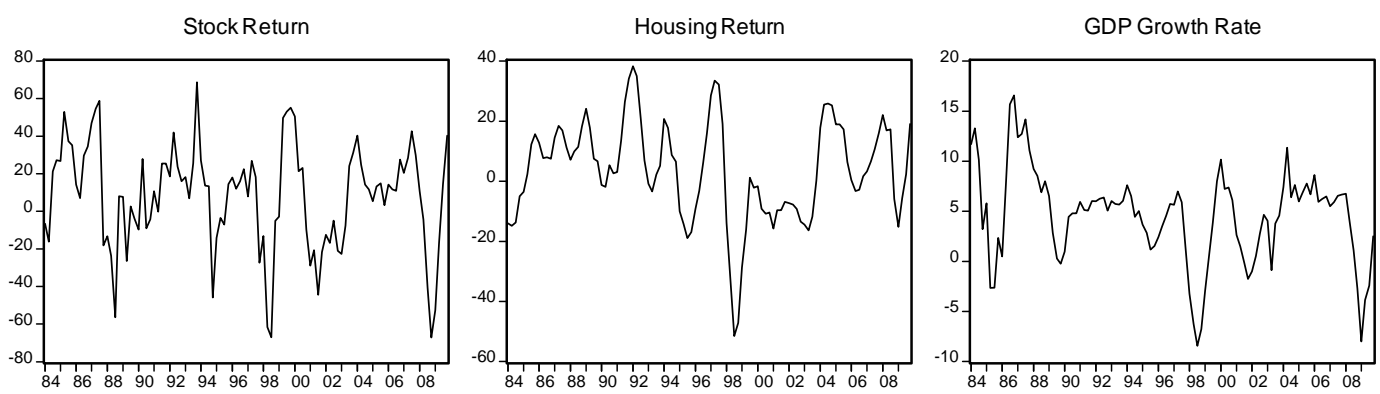

Figure B-2 The time plots for HK data 


\section{Propagation Mechanism}

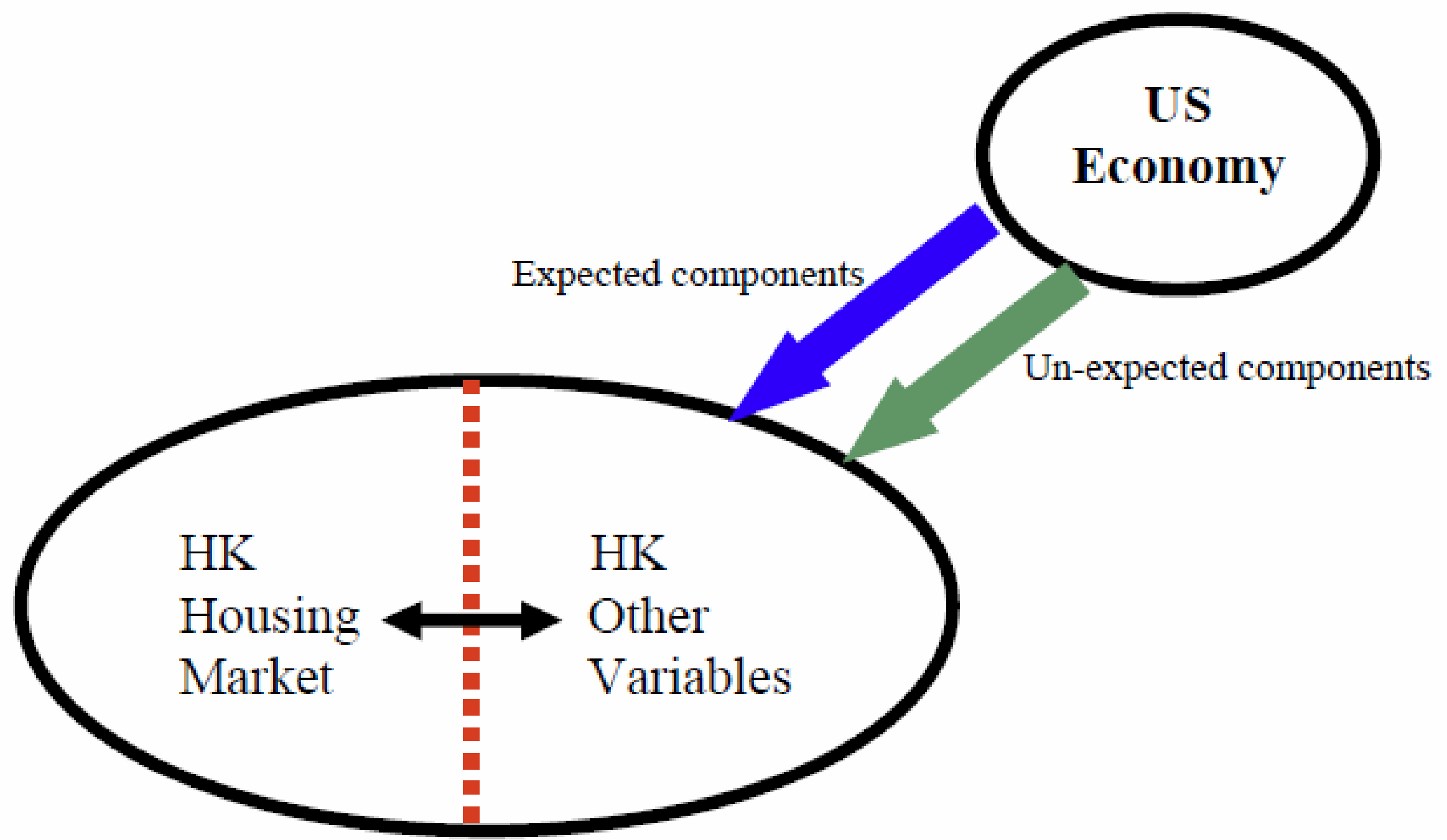

